\title{
I. Der Sohlbergkreis
}

\section{Rendezvous unter Schwarzwaldtannen: Das Sohlbergtreffen 1930}

Zwischen Ottenhöfen und Lautenbach, unweit der Hornisgrinde, ragt aus einem Kranz dunkler Tannen der Gipfel des Sohlbergs. Von diesem 780 Meter hohen westlichen Ausläufer des Schwarzwalds wandert der Blick an schönen Tagen weit hinunter ins Renchtal und in die Rheinebene, am Horizont zeichnet sich die Silhouette des Straßburger Münsters ab.

In solch idyllischer Landschaft kam es im Sommer 1930, vom 28. Juli bis 3. August, zu einer denkwürdigen Begegnung: Rund 100 überwiegend junge Franzosen und Deutsche trafen sich in der neuerrichteten, geräumigen Herberge auf dem Sohlberg zur „ersten überbündischen deutsch-französischen Jugendaussprache“" Wenige Wochen nach Abzug der letzten Besatzer aus dem Rheinland, vielerorts von Kundgebungen mit revanchistischem Unterton begleitet, wollten sie „die kulturelle, religiöse, politische und wirtschaftliche Lage beider Länder in der Nachkriegszeit und die besondere Stellung der jungen Generation in ihr" erörtern ${ }^{2}$. Die meisten deutschen Teilnehmer waren Mitglieder der Arbeitsgemeinschaft Karlsruher Jugendbünde (AKJ), einem Dachverband für rund 40 Gruppen unterschiedlicher politischer und weltanschaulicher Couleur, unter dessen Auspizien die Zusammenkunft stand. Die anwesenden Franzosen gehörten in der Mehrzahl parteipolitisch ausgerichteten Organisationen an, etliche studierten an der Sorbonne oder waren in Paris schriftstellerisch und journalistisch tätig. Auf umfassende Tagesordnungen, Ausschüsse und Resolutionen wurde bewußt verzichtet. Das Camp sollte in erster Linie dem zwanglosen Einander-Kennenlernen dienen, in einer hinreißenden Atmosphäre der Kameradschaft, wie ein begeisterter Chronist vermerkt ${ }^{3}$. Der Tag begann mit Frühsport, „um unseren Gliedern durch kunstgerechte Morgenübungen, Waldlauf und Ballspiel Frische und Beweglichkeit zu geben "4. Nach Referaten, in der jeweiligen Muttersprache des Vortragenden gehalten, in Auszügen übersetzt und vervielfältigt, blieb genügend Muße für Spaziergänge, Ausflüge oder Gespräche im kleinen Kreis, wobei nicht selten eine lebhafte Gestikulation fehlende Sprachkenntnisse ersetzt haben soll. Viel hatten sich die jungen Leute zu erzählen: vom Elend Deutschlands und seiner täglich größer werdenden Arbeitslosigkeit, von Konflikten mit den in Erbfeind-Kategorien denkenden Eltern, vom französischen Sicherheitsbedürfnis und von der Not-

1 Sohlbergkreis deutscher und französischer Jugend, Leitung und Redaktion: Otto Abetz, I (September 1931), S. 2.

2 Ebenda.

3 Bentmann/Vallet/Paty, La réunion franco-allemande du Sohlberg, S. 866.

4 Steinthal, Deutsch-französisches Jugendtreffen auf dem Sohlberg, S. 760 f. 
wendigkeit einer Revision des Versailler Vertrags, von Erziehungs- und Schulfragen, künstlerischen Strömungen, Forschung und Glauben ${ }^{5}$.

Die Vorträge, für welche die Veranstalter zum Teil renommierte Wissenschaftler verpflichtet hatten, behandelten das geistige und politische Leben in beiden Ländern; sie wollten mit den jeweiligen Eigenarten vertraut machen und Verständnis dafür wecken, aber auch Gemeinsamkeiten herausstellen. Der Karlsruher Hölderlin- und Stifterforscher Adolf v. Grolman dozierte über deutsche, Guy Crouzet über französische Gegenwartsliteratur. Theologieprofessor Otto Piper aus Münster analysierte in der deutschen Jugend wirksame religiöse Strömungen, Jacques Chabannes, Chefredakteur der Zeitschrift Notre Temps, bezeichnete die Mystik Bergsons als bestimmend für jene jungen Franzosen, die ob des Verschwindens traditioneller Werte neuen Ufern zustrebten. Dr. Kurt Martin, Karlsruher Kunsthallenchef, verbreitete sich über zeitgenössische Kunst, während der Romanist und Gymnasiallehrer Friedrich Bentmann seine Zuhörer auf „rascher Wanderung durch die Jahrhunderte" Zeugen eines fruchtbaren Gebens und Nehmens zwischen den Nachbarvölkern werden ließ und hervorhob, daß der französische Nationalismus ohne deutsches Gedankengut ebensowenig vorstellbar sei wie die Einigung des Deutschen Reiches ohne die Ideen der Französischen Revolution. Der Studentenfunktionär Cecil Mardrus und der Heidelberger Staatswissenschaftler Arnold Bergstraesser beleuchteten gesellschaftliche Aspekte, Notre Temps-Herausgeber Jean Luchaire und Heinz Dähnhardt die politischen Verhältnisse ihrer Länder. Mit Nachdruck unterstrichen die jungen Leute ihren Willen, die Zukunft aktiv mitzugestalten. Sie diskutierten Lösungsansätze, Europa auf eine Weise zu organisieren, die für einen "guten Deutschen“ wie für einen "guten Franzosen“ akzeptabel wäre. Im Brennpunkt stand hierbei der Plan einer „Europäischen Föderation“, den der französische Außenminister Aristide Briand im Mai 1930 in einem Memorandum dem Völkerbund dargelegt hatte, den die Reichsregierung jedoch ablehnte, weil sie argwöhnte, er leiste insgeheim dem Bemühen Frankreichs und seiner osteuropäischen Verbündeten, den Status quo zu konsolidieren, Vorschub6.

5 Die einzelnen Vorträge und Debatten, auch der beiden Folgekonferenzen 1931 in Rethel und 1932 in Mainz, sind in zeitgenössischen Dokumentationen und historischen Studien detailliert wiedergegeben. Es erscheint deshalb nicht zuletzt aus Platzgründen statthaft, das Hauptaugenmerk auf Aussagen zu richten, die die jeweilige Atmosphäre, Erfolg oder Mißerfolg der Tagungen spiegeln. Zum Sohlbergtreffen siehe neben den zitierten Berichten von Bentmann/Vallet/Paty und Steinthal vor allem die ganz diesem Ereignis gewidmete Sonderausgabe von Notre Temps vom 10.8.1930, Le congrès du Sohlberg 27 juillet3 août 1930. Compte rendu et exposés; Eine deutsch-französische Jugendbegegnung auf dem Sohlberg, in: Das junge Volk. Zeitschrift des Jungen Deutschland 2 (September 1930), S. 144 f.; Crouzet, Huit jours franco-allemands au Sohlberg, in: La Grande Revue, August 1930, S. 193-202; Luchaire, Au camp de Sohlberg. Une expérience franco-allemande, in: La Volonté, 8. 8. 1930. Abetz, Das offene Problem, S. $27 \mathrm{ff}$;; ders., „Denkschrift betr. deutsch-französisches Jugendtreffen auf dem Sohlberg im Schwarzwald, 28. Juli-3. August 30" (masch. 7 S.), 30. 4. 1931, AdJb, A 168/1; dieses Dokument wird uns an anderer Stelle noch näher beschäftigen. Siehe ferner Hardenberg, Bündische Jugend; Tiemann, Jugendbeziehungen, S. 114-119; Unteutsch, Sohlbergkreis, S. 52-57.

6 Zum französischen Europa-Memorandum Knipping, Ende der Locarno-Ära, S. 155-161. 
Bei aller Ernsthaftigkeit der Gespräche kam das Gesellige nicht zu kurz. Kammermusik und Laienspiel bereicherten das Programm. „Und lustig sind wir da oben gewesen“, notierte ein Teilnehmer, „bei Tische, im gemeinsamen Schlafsaal, [...] wenn die deutsche Jugend ihre fröhlichsten Lieder zur Klampfe sang, da sprudelte der Übermut. Sogar einen Tanzabend gab es, wo sich denn die feingliedrige Südfranzösin, die graziöse Pariserin mit den schwarzen Locken gar seltsam von dem geruhsamen deutschen Gretchen mit den hellblonden Flechten abhob. "7 Auch dem verwöhnten Gaumen der Gäste wurde schmunzelnd Rechnung getragen, nachdem sie beim Anblick eines dampfenden, bodenständigen Nudeleintopfs scharenweise in die Restaurants der näheren Umgebung geflüchtet waren ${ }^{8}$. Nach einer Woche trennte man sich im Bewußtsein einer "gemeinsamen Identität“, die künftig zum Nutzen aller Früchte tragen sollte. Im Schein eines mächtigen Lagerfeuers gelobten die Sohlbergfahrer, mit gutem Beispiel voranzugehen und die begonnene Arbeit nicht eher ruhen zu lassen, bis ihre Völker sich versöhnt hätten, eingedenk der Worte Romain Rollands: „Wir sind die beiden Flügel des Abendlandes. Wer den einen zerstört, lähmt den Flug des anderen."9

$\mathrm{Zu}$ denen, die am 3. August ihr Ränzlein schnürten und heimkehrten, gehörte ein 27jähriger Studienassessor und Kunsterzieher aus Karlsruhe, ein ehemaliger Wandervogel voller Tatendrang, der sich berufen fühlte, auf eine gütliche Nachbarschaft am Rhein hinzuwirken: Otto Abetz. Im Bemühen, einen von seiner Generation geführten Dialog zwischen zwei Nationen, die sich nach verlustreichen Kriegen noch immer belauerten, in Gang zu setzen, hatte er das Sohlbergtreffen organisiert. Mit badischem Humor und Improvisationsgabe, aber auch durch sein bescheidenes Auftreten gewann er die Sympathien der jungen Franzosen, in deren Augen er die sprichwörtliche gute Seele einer harmonisch verlaufenen Zusammenkunft war ${ }^{10}$. „Sie sahen in ihm das Urbild des romantischen Deutschen, eine moderne Abart des Siegfried“, berichtet in etwas überschwenglicher Manier sein Jugendfreund und späterer Schwager Friedrich Bentmann. „Vor allem spürten sie: Hier steht einer, der sich nicht ehrgeizig oder eitel herausstellen will. Ihm geht es um die Sache, um die Idee, daß die junge Generation beider Länder nach so vielem Blutvergießen, nach ständigem Mißtrauen und Mißverstehen zueinander finden will." 11 Fortan spielte die deutsch-französische Frage, dieses „offene Problem“, eine dominierende Rolle in seinem Leben.

Die ablehnende Antwortnote der Reichsregierung vom 11.7.1930 ist abgedruckt in ADAP, B XV, Nr. 136.

7 Steinthal, Deutsch-französisches Jugendtreffen, S. 761.

8 Abetz, Das offene Problem, S. 28.

9 Rollands in verständigungsbereiten Kreisen vielzitierter Satz findet sich in La nouvelle journée, Paris 1912, S. 230. Der Autor läßt in diesem zehnten und letzten Band des Romanzyklus Jean-Christophe seinen Helden angesichts des übersteigerten Nationalismus jener Zeit über die schicksalhafte Verbundenheit Frankreichs und Deutschlands reflektieren.

$10 \mathrm{Vgl}$. die lobenden Worte Luchaires in Notre Temps, 10. 8. 1930, Sp. 359.

11 Bentmann, Über Otto Abetz, S. $57 \mathrm{f}$. 


\section{Fluch und Segen einer Nachbarschaft: Jugendjahre im badischen Grenzland}

Otto Friedrich Abetz wurde am 26. März 1903 in Schwetzingen, unweit des nordbadischen Industriereviers Mannheim geboren ${ }^{12}$. Die fünf Jahrzehnte währende Regentschaft von Großherzog Friedrich I., der mit der katholischen Kirche zäh um ihre Rechte im Staat gerungen hatte, auf österreichischer Seite in den deutschen Krieg gezogen war und das erste Hoch auf Wilhelm I. anläßlich der Kaiserproklamation in Versailles schmetterte, neigte sich damals dem Ende zu. Der Karlsruher Rheinhafen war vor kurzem eröffnet worden und ein allgemeines, direktes Wahlrecht für den Landtag nicht mehr fern.

Ottos Vater, auf denselben Vornamen getauft, kam 1863 in Rastatt als Sohn eines Wagnermeisters zur Welt. Dieses Handwerk besaß Tradition in der Familie, Otto sen. aber entschied sich für eine Beamtenlaufbahn in markgräflichen Diensten $^{13}$. Mutter Anna Wilhelmine, geborene Laumann, Tochter eines Gutsbesitzers aus der Nähe von Worms, zählte Jäger und Förster zu ihren Ahnen. Die Eheleute hatten zwei weitere Kinder, Maria, die den Curtius-Schüler Friedrich Bentmann heiratete, und Karl (1896-1964), der sich als Forstwissenschaftler, zuletzt an der Universität Freiburg, einen Namen machte. Nach der Jahrhundertwende bewohnte die Familie Abetz Dienstgemächer im Schwetzinger Schloß. Die mittelalterliche, zur Barockzeit ausgebaute Wasserburg und der angrenzende, prachtvolle Park mit Blumenbeeten, Kastanienalleen und Wasserspielen gaben das Ambiente für Ottos frühe Kindheit. Jugendfreund Bentmann beschrieb das Elternhaus als „sehr eigenartig, um nicht zu sagen kurios"14. Vater Abetz wird als eigenbrötlerischer, pflichtversessener Tyrann geschildert, während seine Frau, warmherzig und lebensklug, den Kindern offenbar vieles nachsah.

1908/09 wurde Abetz sen. in die Landeshauptstadt Karlsruhe versetzt ${ }^{15}$. Dort besuchte Otto von 1911 an das Goethe-Realgymnasium. Er verabscheute Mathematik, glänzte im Deutschunterricht. 1913 trat er dem „Wandervogel e.V., Bund

12 Biographische Daten sind, soweit nicht anders vermerkt, den nachstehend genannten Quellen entnommen: „Fragebogen zur Berichtigung bzw. Ergänzung der Führerkartei der SS-Personalkanzlei" vom 2. 12. 1936; handgeschriebener Lebenslauf vom 23. 8. 1937; Abetz an Obergebietsführer John (RJF-Personalamt), 1. 9. 1937; genealogische Aufzeichnung Abetz' vom 10. 12. 1937; sämtliche BDC, SS-Personalunterlagen Abetz. „Curriculum vitae d'Otto Abetz “ (9S.), am 16.11. 1945 von französischen Polizeikommissaren protokolliert und von Abetz per Unterschrift bestätigt; AN, F7/15331. Protokoll einer Vernehmung durch Dr. John H. E. Fried am 28. 5. 1947 im Pariser Gefängnis ChercheMidi; StA Nürnberg, KV-Anklage, Interrogations, A 2 (ein unvollständiges Exemplar unter der Signatur LXXI-124 im Pariser CDJC). Abetz, Das offene Problem, S. 15 ff.; Ottnad (Hrsg.), Badische Biographien, N. F., Bd. 1, S. 5 ff.

13 Den oben aufgeführten Quellen zufolge bekleidete er im Jahre 1903 den Posten eines Rentamtmanns und wurde 1909 zum Domänenrat befördert. Der Geburtseintrag des Sohnes im Schwetzinger Standesamtsregister weist ihn dagegen schon 1903 als Markgräflichen Domänenrat aus.

14 Bentmann, Über Otto Abetz, S. $51 \mathrm{f}$.

15 Die meisten Quellen nennen das Jahr 1909, im Schwetzinger Adressbuch fehl $\tau$ der Name Abetz jedoch schon 1908. Mitteilung des Stadtarchivs Schwetzingen vom 22. 3. 1993. 
für deutsches Jugendwandern" bei, der im Jahr des 1. Freideutschen Jugendtags auf dem Hohen Meißner die meisten Wandervogel-Gruppierungen vereinigt hatte und in diesem Spektrum tonangebend, wiewohl stets von Spaltungen bedroht war $^{16} .1920$ zählte der Pennäler Abetz zu den ersten Köpfen des Karlsruher Wandervogels. Zwei Jahre später, der „e.V.“ war an Rivalitäten und programmatischen Auseinandersetzungen - etwa über die Frage der Mitgliedschaft von Mädchen zerbrochen, schloß er sich einer Nachfolgeorganisation an, dem „Wandervogel, Wehrbund Deutscher Jugend“. Dieser Verein war nicht militaristisch ausgerichtet, wie der Name vermuten lassen könnte, sondern wollte das Ideal kämpferischen Einsatzes zum Nutzen aller pflegen: "Wehrhaft ist uns derjenige, dessen Charakter in Gemeinschaftsjahren entwickelt und gestählt, dessen Denken objektiv, sozial und souverän, dessen Wesen harmonisch-geschlossen und aristokratisch sich unbedingt im Leben behauptet und der alle seine Kraft in den Dienst der Allgemeinheit stellt." ${ }^{17}$ Der Wandervogel-Wehrbund stieß alsbald zur Bündischen Jugend und bildete zusammen mit anderen Gruppen den „Wandervogel, Deutsche Jungenschaft", der 1926/27 in der "Deutschen Freischar" aufging. Abetz schied bereits 1924 unter ungeklärten Umständen aus.

Das Eintauchen in Lebensformen und Gefühlswelt der bürgerlichen, um das Jahr 1920 in ihre bündische Phase eintretenden Jugendbewegung, die neben beachtlichem reformerischem Potential auch romantische, rückwärtsgewandte Züge besaß, nannte er "mein entscheidendes Jugenderlebnis" 18 . Hervorstechende Charaktereigenschaften des jungen Abetz spiegeln in der Tat milieutypische Einflüsse: Idealismus, Begeisterungsfähigkeit und Reiselust zeichneten ihn genauso aus wie das unbedingte Festhalten an einmal gesteckten Zielen, jugendbetontes Sendungsbewußtsein und der Wille zur mitverantwortlichen Neugestaltung überkommener Verhältnisse. Als nach dem Ersten Weltkrieg politische und gesellschaftliche Fragen zunehmend ins Blickfeld der heranwachsenden Generation rückten, gehörte er zu denen, die europäische Zusammenhänge verstehen lernen wollten und die Begegnung mit Altersgenossen aus anderen Ländern suchten, um gegenseitiges Verständnis bemüht, ohne deshalb nationale Positionen preiszugeben. Als klassisches Verhaltensmuster erscheint auch der Versuch, im kleinen, verschworenen Kreis Gleichgesinnter auf lokaler Ebene etwas in Gang zu setzen, so wie Abetz es Ende der zwanziger Jahre als Vorsitzender der Arbeitsgemeinschaft Karlsruher Jugendbünde praktizierte. Seine letztlich doch fatale Empfänglichkeit für Führertum und Volksgemeinschaft, großdeutsches Denken und Reichsidee entsprang ebenfalls jugendbewegten Leitbildern und war geeignet, seine spätere Integration ins Hitler-Regime zu begünstigen ${ }^{19}$.

16 Kneip, Jugend der Weimarer Zeit, S. 238 ff.; Schneider, Daten zur Geschichte der Jugendbewegung, S. 9.

17 Zit. bei Kneip, Jugend, S. 245.

18 Abetz, Das offene Problem, S. 15.

${ }_{19} \mathrm{Zu}$ den Wertvorstellungen der deutschen Jugendbewegung bis 1933 , hier lediglich summarisch hinsichtlich ihrer Prägekraft auf Abetz angerissen, siehe unter vielen: Fick, Die deutsche Jugendbewegung; Raabe, Bündische Jugend; Laqueur, Die deutsche Jugendbewegung; Kindt (Hrsg.), Die deutsche Jugendbewegung 1920 bis 1933. Die bündische Zeit; Giesecke, Vom Wandervogel bis zur Hitlerjugend; Jovy, Jugendbewegung und National- 
Nachhaltig geprägt hat ihn zum anderen der Erste Weltkrieg. Er entstammt jener „Kriegsjugendgeneration“20, die zu jung für die Front war, die Auswirkungen des Schlachtentaumels aber schon bewußt wahrnahm: tiefgreifenden Wandel der Lebensbedingungen, Hunger und Tod, schließlich den Zusammenbruch des Vaterlandes, revolutionäre Wirren und Wirtschaftsnot. Erzogen nach den Konventionen des Kaiserreichs, reifte sie in einer spannungsgeladenen, krisenhaften Zeit des Umbruchs. Karl Epting, 1905 geboren, taufte sie "Generation der Mitte“, nicht zuletzt weil sie aufgrund ihres friedlosen Erfahrungshorizonts um Mäßigung und Ausgleich bemüht gewesen sei ${ }^{21}$, eine Bewertung, die Abetz' Selbstverständnis nahekam. "Grenzland"-Erlebnisse markieren den Ausgangspunkt seiner Entwicklung zum Mittler. Die Spuren früherer deutsch-französischer Konflikte, in Baden allgegenwärtig, waren schon dem Knaben nicht verborgen geblieben22; im Weltkrieg zeigte sich erneut, welche Abgründe die Nachbarn am Rhein trennten, was ihre Feindschaft anzurichten vermochte. Zwar blieb der Südwesten Deutschlands von Erdkämpfen verschont, doch war er als Aufmarschgebiet besonderen Belastungen ausgesetzt. Von den Vogesen hallte Gefechtslärm herüber. Luftangriffe, die zunächst Rüstungsbetrieben in Mannheim und Karlsruhe galten, in wachsendem Maße aber auch die Zivilbevölkerung in Mitleidenschaft zogen, verbreiteten Angst und Schrecken. Insgesamt zwölfmal belegten alliierte Flugzeuge die badische Metropole mit Bomben ${ }^{23}$. Bei der folgenschwersten Attacke am Fronleichnamstag 1916 starben 82 Kinder, Besucher einer Tierschau auf dem Festplatz ${ }^{24}$. Der 13jährige Abetz mußte damals mit ansehen, „wie verzweifelte Mütter zwischen den in langen Reihen gelagerten und mit Tüchern verdeckten Kinderleichen herumirrten und nach ihren vermißten Buben und Mädchen such-

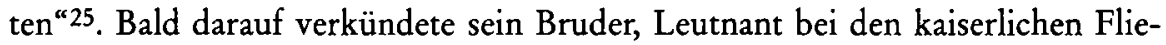
gern, daß er mit seinem Geschwader eine französische Stadt angreifen werde. Der Gedanke, Karl könnte den Tod unschuldiger Kinder verursachen, habe ihm das

sozialismus. Populärwissenschaftlich aufbereitet, gleichwohl informativ Malzacher/ Daenschel, Jugendbewegung für Anfänger.

20 Raabe, Bündische Jugend, S. 26, rechnet hierzu die Jahrgänge 1900 bis 1907. Fast dieselbe zeitliche Zuordnung und Definition bei Bertrand de Jouvenel (geboren 1903), Un voyageur dans le siècle, $\mathrm{S}$. $76 \mathrm{f}$.

21 Epting, Generation der Mitte, S. 3. Er verlieh dieses Prädikat den Jahrgängen 1900 bis 1910.

22 Abetz, Das offene Problem, S. 17.

${ }^{23}$ Hugo Ott, Die wirtschaftliche und soziale Entwicklung von der Mitte des 19. Jahrhunderts bis zum Ende des Ersten Weltkriegs, in: Badische Geschichte, hrsg. von der Landeszentrale für politische Bildung Baden-Württemberg, S. 141.

24 Schulthess' Europäischer Geschichtskalender 1916, I, S. 326 f.

25 Mit Henri de Kerillis, dem Kommandeur der todbringenden Schwadron, hat Abetz manchen Strauß ausgefochten. Zu Beginn der dreißiger Jahre lehnte es der nun als Journalist tätige Franzose ab, als versöhnliche Geste einen Kranz an den Gräbern der Opfer niederzulegen. Abetz fand wenig schmeichelhafte Worte für ihn. Seinen SS-Oberen sagte er 1937, Kerillis sei „neben den Kommunisten und Juden der größte Deutschenfresser, den es in Paris gibt"; "Vernehmungsniederschrift" vom 7. 12. 1937, pag. 4, BDC/Abetz. 1939 leitete Kerillis eine Pressekampagne gegen den Deutschen, der unter anderem der Spionage und Wehrkraftzersetzung bezichtigt wurde (siehe Kap. VII). 
Herz zusammengeschnürt, beschrieb Otto Jahre später seine Empfindungen ${ }^{26}$. Erschütternde Einblicke in die Leiden der Truppe bestärkten nur seine „Feindschaft gegen alles, was zu Kriegen führt und die menschliche Wildheit in ihnen

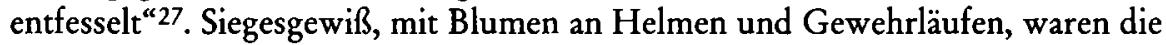
Grenadiere im August 1914 ins Feld gezogen; doch schon bald liefen Züge mit Verwundeten in Karlsruhe ein, trugen Sanitäter wimmernde, zerschossene Soldaten aus der Bahnhofshalle.

Gegen Ende des Krieges huldigte Abetz, beeinflußt von aus Norddeutschland stammenden, zum Heeresdienst nach Karlsruhe versetzten Führern der "Freideutschen Jugend", linksradikalen, internationalen Tendenzen. Mit seinen Klassenkameraden schwärmte er für Völkerfrieden und Weltverbrüderung, und da sich der Zeitgeist allerorten in Räten manifestierte - eine am 10. November 1918 gebildete provisorische Landesregierung stützte sich auf Arbeiter- und Soldatenräte, im Februar 1919 sorgte die versuchte Ausrufung einer Räterepublik in Mannheim für blutigen Tumult ${ }^{28}$-, hatte er nichts Eiligeres zu tun, als einen Schülerrat zu gründen ${ }^{29}$. Ebenso rasch aber erloschen seine Sympathien für die revolutionäre Linke wieder, weil er es beschämend fand, daß Umstürzler heimkehrenden Soldaten Orden und Rangzeichen herunterrissen. Karl Abetz, im Luftkampf abgeschossen und schwerverletzt geborgen, entging nur knapp tätlichen Angriffen, als er an Krücken durch Karlsruhe humpelte. Von da an, erzählte Otto dem Pariser Publizisten Bertrand de Jouvenel, sei er "national“ eingestellt gewesen, wobei sein Zorn keineswegs den siegreichen Franzosen, sondern jenen Landsleuten gegolten habe, die die Niederlage nicht mit Anstand ertrugen ${ }^{30}$. Kriegsgegnerschaft war für ihn mit der Anerkennung soldatischer Tapferkeit also durchaus vereinbar; umgekehrt hielt er gerade die Veteranen für legitimiert, neuen Feindseligkeiten entgegenzuwirken. Wenn er sich in den dreißiger Jahren bemühte, diese Männer zu „Waffenbrüdern“ seiner Generation zu machen, so mag ihm dies der Respekt, den er den Frontkämpfern seit Schülerzeiten zollte, in besonderem Maße nahegelegt haben. Auch konnte er sich Hitler insoweit verbunden fühlen, als dieser die ehrlose Behandlung von Kriegsheimkehrern anzuprangern und ihnen eine herausragende Rolle bei der Verhütung künftiger Kriege zuzuschreiben pflegte ${ }^{31}$.

26 Brinon, Anmerkungen zu Abetz, aufgezeichnet im Vorfeld des Brinon-Prozesses 1947; AN, 411 AP 6.

27 Abetz, Das offene Problem, S. 19.

28 Hans Georg Zier, Politische Geschichte Badens 1918 bis 1933, in: Badische Geschichte, S. 148. Ausführlich Brandt/Rürup (Bearb.), Arbeiter-, Soldaten- und Volksräte in Baden $1918 / 19$.

29 Abetz, Das offene Problem, S. 20.

30 Abetz berichtete Jouvenel, den er 1931 in Rethel kennenlernte, Einzelheiten des Zwischenfalls: Der Pöbel habe seinen Bruder in einen Hauseingang gezerrt und ihm die Auszeichnungen weggenommen. Weinend, eine Krücke zerbrochen, sei Karl nach Hause gekommen. Vgl. Jouvenel, Voyageur, S. $200 \mathrm{f}$.

31 Einige Beispiele unter vielen: Jäckel/Kuhn (Hrsg.), Hitler. Sämtliche Aufzeichnungen 1905-1924, S. 235, 1008; Hitler, Mein Kampf, S. 250f. Einen auf Verständigung zielenden Impetus bei Veteranen nahm der Weltkriegsgefreite Hitler stets geschickt auch für sich in Anspruch. Noch am 27. August 1939 schrieb er Daladier, als alter Frontsoldat, der die 
Ein Anhänger der „Dolchstoß"-Legende, wonach die Armee 1918 in der Heimat geschlagen worden sei, war Abetz jedoch nicht.

Die Zeit der französischen Besatzung streift er in seinen Memoiren nur kurz und anekdotenhaft. Er erinnert sich farbiger Söldner, die im Winter auf einer Rheinbrücke frierend Wache schoben. „Mit der Grausamkeit der Jugend warfen wir vor ihren Augen die Kleider ab und schwammen [...] einige Stöße zwischen den Eisschollen des reißenden Stromes. Das winterliche Bad wurde gern in Kauf genommen, nur um uns daran zu weiden, wie die Söhne des heißen Erdteils vor Schrecken geschüttelt wurden." 32 Der grimmige Unterton läßt ahnen, wie gespannt das Verhältnis zwischen Einheimischen und Besatzern war. Die Niederlage von 1918 traf Baden härter als andere deutsche Länder. Zwar vollzog sich der Übergang von der konstitutionellen Monarchie zur parlamentarischen Demokratie, eingeleitet durch die Abdankung des Großherzogs, vergleichsweise reibungslos. Doch wurden die ohnehin drückenden Folgelasten des Krieges - Demobilmachung, Reparationen, Inflation - im Südwesten durch einige Faktoren verschärft, die aus der geographischen Lage und der französischen Deutschlandpolitik resultierten. Die Rückgabe von Elsaß-Lothringen an Frankreich zerschnitt wirtschaftliche Verflechtungen und bescherte einen Strom von Aussiedlern; Handelsvereinbarungen des Versailler Vertrags, zollrechtlich von Nachteil, lähmten zusätzlich die Konjunktur. 1919 wurde eine 50 Kilometer breite entmilitarisierte Zone geschaffen, rund um Kehl bildeten die Franzosen bis 1930 einen Brückenkopf. Vom Reich vollends im Stich gelassen wähnten sich die Badener während des Ruhrkampfes 1923/24, der eine mehr als 18 Monate dauernde Besatzung einiger Landesteile und der Rheinhäfen Karlsruhe und Mannheim mit sich brachte ${ }^{33}$. In der Bevölkerung machte sich ein Gefühl der Schutzlosigkeit und Randexistenz breit. Es hätte kaum verwundert, wäre Otto Abetz aufgrund dieser Erfahrungen wie so mancher seiner Landsleute in antifranzösischen Ressentiments erstarrt.

Freund Bentmann schildert den angehenden Abiturienten als naturverbundenen Jüngling mit wilder Haartolle, von Fernweh geplagt, ein Künstlertyp mit antibürgerlichem Habitus, der für Rilke schwärmte ${ }^{34}$. Er verriet zeichnerisches Talent; sein Vater, während des Krieges als Hauptmann der Reserve bei der Heeresverwaltung tätig, hätte ihn jedoch lieber in eine Bank gesteckt. Über den innerfamiliären Konflikt, der sich hieran entzündete, kursieren zwei voneinander abweichende Darstellungen. Bentmann zufolge einigte man sich auf eine Buchhändlerlehre, doch in dem dafür ausersehenen, etwas angestaubten Laden hielt es Otto nicht lange aus. Er brannte durch, trieb sich eine Zeitlang in Italien und der Schweiz herum, verdingte sich auf einem Bauernhof am Bodensee. Abetz selber verbreitete eine Version, die sein Handeln überlegter, weniger impulsiv erscheinen

Schrecken des Krieges kenne, habe er sich um einen Ausgleich bemüht. Zit. bei Domarus, Hitler, Bd. II, S. $1274 \mathrm{f}$.

32 Abetz, Das offene Problem, S. 21.

33 Zier, Politische Geschichte Badens, S. 149 f.; Hermann Schäfer, Wirtschaftliche und soziale Probleme des Grenzlandes, in: Badische Geschichte, S. 168-183; Hug, Geschichte Badens, S. $312 \mathrm{ff} ., 318$.

34 Bentmann, Über Otto Abetz, S. 52 ff., auch zum Folgenden. 
läßt: Nach dem Abitur will er eine 18monatige (!) Studienreise nach Italien und Griechenland unternommen haben, um die Kunstschätze der Antike und Renaissance kennenzulernen ${ }^{35}$. Einzelheiten, etwa zur Finanzierung, blieb er schuldig. In seinen Memoiren, die auch diesen Lebensabschnitt kursorisch behandeln, erwähnt er ferner, wie jeder zünftige Wandervogel "gesiedelt“ zu haben. In seinem Fall bedeutete das landwirtschaftliche Tätigkeit und Mitarbeit beim Aufbau eines Landschulheims am Bodensee ${ }^{36}$.

Erleichtert über die Heimkehr des „verlorenen Sohnes", gestattete der Vater schließlich den Besuch der Badischen Landeskunstschule ${ }^{37}$. Abetz immatrikulierte sich im Jahre 1922 und wurde Meisterschüler der Fachklasse Holzschnitt. Sein Lehrer Ernst Würtenberger, bekannt geworden durch Holzschnitt-Illustrationen zu Gottfried Kellers Novellen und eine wissenschaftliche Abhandlung über den Maler Ingres, bewunderte als Verfechter eines linearen Stils und geordneten Bildaufbaus die traditionelle, formenstrenge französische Schule. Auch darüber hinaus brachte das Studium Abetz zunehmend mit französischer Kultur in Berührung. Sein Interesse am Nachbarland wurde hierbei nachhaltig geweckt; über die Beschäftigung mit Kunst und Literatur fand er "die entscheidende Brücke zu Frankreich“38. Ein Lesezirkel des frankophilen Literaturhistorikers Adolf v. Grolman machte ihn mit französischem Schrifttum vertraut ${ }^{39}$. Der Kunsthistoriker Waltzinger entführte ihn in die Welt gotischer Kathedralen nach den persönlichkeitsbildenden Einflüssen des Wandervogels und der vom deutsch-französischen Gegensatz geprägten „Grenzland“-Jugend ein drittes Schlüsselerlebnis, denn hier entdeckte er inneren Gleichklang und ursprüngliche Einheit abendländischer Kultur. „Da spannte sich mir ein Bogen zwischen dem Mont Saint-Michel und der Marienburg [...] Ich erkannte, daß das größte Bildwerk der Deutschen, der Reiter im Bamberger Dom, eines Blutes und eines Geistes mit seinem königlichen Ebenbild in der Reimser Kathedrale war, daß Bürgerschaften, die solche gewaltigen Kirchenhallen zum Himmel türmten, noch eine gemeinsame Sprache des Herzens geredet hatten. ${ }^{"} 40$

Damit war es zu Beginn der zwanziger Jahre nicht mehr weit her. Die Deutschen litten unter bürgerkriegsähnlichen Unruhen, Reparationslasten und Geldentwertung und machten Frankreich, das eine buchstabengetreue Erfüllung des Versailler Vertrags erzwingen wollte, für ihre Not verantwortlich. Zur selben Zeit, da Abetz beglückt eine "seelische Verwandtschaft" und einander befruchtende

35 „Curriculum vitae d'Otto Abetz“ (1945), pag. 2; AN, F7/15331. Abetz-Prozeß, 12. 7. 1949, pag. 11; AN, 334 AP 49. Das offene Problem, S. 24, allerdings ohne Angabe der Aufenthaltsdauer. Diese Überlieferung fand Eingang in zahlreiche biographische Skizzen, u. a.: Mitteilung der Agentur Interpress Hamburg, „Otto Abetz. Ein Deutscher aus Frankreich - Zuerst das Palais, dann die Zelle“, Nr. 82/1954, 9. 4. 1954; Internationales Biographisches Archiv (Munzinger-Archiv), Lieferung 22/58 vom 31. 5. 1958.

36 Abetz, Das offene Problem, S. 22.

37 Wir folgen hier der glaubhaft klingenden Darstellung Bentmanns, wie Anm. 34.

38 Protokoll einer Vernehmung Abetz' durch Robert Kempner und M. Orthmann am 6. 7. 1948, pag. 18; StA Nürnberg, KV-Anklage, Interrogations, A 2.

39 Friedrich Bran bezeichnete v. Grolman als Abetz' „Mentor“; Befragung Bran, 18. 3. 1989.

40 Abetz, Das offene Problem, S. 23. 
„Kulturgemeinschaft“ beider Völker konstatierte, fühlte er sich französischen Kanonen ausgeliefert. Als "Fluch und Segen einer Nachbarschaft" hat er diesen Dualismus empfunden, der ein janusköpfiges Frankreichbild formte und künftigem Handeln die Richtung wies: Dem „Frankreich der Gewalt" sollte sein „ganzer $\mathrm{Haß}$ “, dem „Frankreich des Geistes" seine „ganze Liebe" gelten ${ }^{41}$. Noch während des Studiums begann er - eigenen Angaben zufolge -, in örtlichen Jugendpostillen Verständigung zu predigen ${ }^{42}$. Leitmotiv und zentrales Argument seines Werbens war das Wissen um eine längst vergangene „Einheit" - verklärend festgemacht am Reich Karls des Großen - und gemeinsame kulturelle Wurzeln; in seinen Augen bildeten sie ein unzerstörbares, tiefenwirksames Bindeglied, stärker als jeder politische Zwist, wie Abetz auch Jahre später, mit nationalsozialistischem Zungenschlag, doch unvermindert am einheitstiftenden Primat des Geistes festhaltend, unter Verwendung eines Hitler-Zitats emphatisch hervorhob: „Quel rôle jouent [...] deux ou trois millénaires dans l'humanité? Des peuples montent, des peuples périssent, mais les grandes bases des races subsistent. La langue, comme les formations des états n'ont toujours amené qu'à créer des confusions, à effacer les traces de l'origine commune et à ériger des murs entre ceux que la nature, à travers des dizaines de millénaires, a formé de la même matière et de la même âme. " ${ }^{33}$

1927 fand er, nach dem Staatsexamen und einem kurzen Gastspiel an der Rotteck-Oberrealschule Freiburg, eine Anstellung an einem Karlsruher Gymnasium. Im darauffolgenden Jahr starb der Vater. Abetz wohnte bei seiner Mutter, die wenig Geld hatte - eine Spätfolge der Inflation - und gelegentlich ein Möbelstück versetzen mußte ${ }^{44}$. Im September 1927 kürte die Arbeitsgemeinschaft Karlsruher Jugendbünde (AKJ) den geselligen Junglehrer zu ihrem Vorsitzenden. Anscheinend völlig überrascht, willigte Abetz ein. Später erklärte er das Votum damit, daß die Abstimmenden seine Unparteilichkeit schätzten; seit seinem Austritt aus dem „Wandervogel-Wehrbund" hatte er sich keiner Formation mehr angeschlossen ${ }^{45}$. $\mathrm{Daß}$ die Wahl gerade auf ihn fiel, deutet jedoch darauf hin, daß er zumindest bis 1924 eine nicht ganz unwichtige Rolle in Kreisen der Karlsruher Jugend spielte. Neutralität und Toleranz waren in seinem neuen Amt gefragt, denn in der AKJ begegneten sich so gegensätzliche Temperamente wie Völkische, Sozialdemokraten und Kommunisten, Katholiken, Protestanten und Juden, Studenten, Sportler und Gewerkschafter. Bürgerliche Nationalisten trafen auf linksrevolutionäre Weltverbesserer, lebensreformerische Vorstellungen mischten sich mit sittlich-

41 Ebenda, S. 25. Unteutsch, Sohlbergkreis, S. 246, verweist in diesem Zusammenhang auf eine zunehmende Fluchtbewegung des Bildungsbürgertums ab der Jahrhundertwende in geistige Sphären, von der Überzeugung geleitet, daß Geist und Macht gegensätzliche Kräfte seien.

42 "Curriculum vitae d'Otto Abetz", pag. 2; AN, F 7/15331. Die gleiche Darstellung schon bei Lazareff, Dernière édition, S. 68. Zeugnisse dieses frühen Engagements konnten nicht ermittelt werden.

43 Otto Abetz, A la recherche de l'Occident, in: DFM, Januar-Februar 1935, S. 115-118, das Zitat S. 118.

${ }^{44}$ So überliefert von einem guten Bekannten aus Sohlbergtagen, André Weil-Curiel, Le temps de la honte, Bd. II, S. 123.

45 Abetz an John, 1. 9. 1937; BDC/Abetz. „Curriculum vitae", pag. 2; AN, F7/15331. 
religiösen - ein beeindruckendes Beispiel für die wiederholt beschriebene Fähigkeit jugendbewegter Gemeinschaften, einander gelten zu lassen und auf der Grundlage persönlicher Verbundenheit alle möglichen Überzeugungen und Gesellschaftsschichten zusammenzuführen ${ }^{46}$. Eine Kehrseite der Medaille war, daß eine Abgrenzung gegen extreme, totalitäre Kräfte häufig, so auch in Karlsruhe, unterblieb.

Nestabende der einzelnen Gruppen, Laienspiel, Sing- und Tanzkreise bestimmten den Ablauf im städtischen Jugendheim, über das die Arbeitsgemeinschaft verfügen konnte. Abetz indessen setzte bald andere Akzente, indem er einen Arbeitskreis für Auslandsfragen gründete, der im besonderen ein Treffen mit jungen Franzosen arrangieren wollte. Ein solches Vorhaben befürworteten im Juli 1929 sämtliche in der AKJ vereinten Bünde, ,auf Grund ihrer überparteiischen Zusammensetzung, der fränkisch-alemannischen Stammesverwandtschaft und der günstigen Lage Karlsruhes als nächstgelegener deutscher Großstadt der Westgrenze ${ }^{\star 47}$. Die kommenden Monate dienten der inhaltlichen Vorbereitung des Projekts: Vorträge und Diskussionen vermittelten Kenntnisse über französische Geschichte und Kultur und untersuchten die aktuellen Beziehungen zwischen den Ländern ${ }^{48}$. Tatkräftige Unterstützung leistete Walter Strauss, ein jüdischer Bankierssohn, der für französische Kunst und Lebensart schwärmte ${ }^{49}$. Ostern 1930 fuhren Abetz und Friedrich Bentmann nach Paris, um direkten Kontakt aufzunehmen und zu einer Aussprache in den Schwarzwald einzuladen. Das war, nimmt man die Rahmenbedingungen jener Zeit als Maßstab, keine Selbstverständlichkeit, wie der folgende Exkurs verdeutlichen soll.

46 Jovy, Jugendbewegung und Nationalsozialismus, S. 2, 38; Raabe, Bündische Jugend, S. 44 f., 112, S. 48: „Das Moment der Soziabilität war aber das entscheidende, die ideelle oder ideologische Programmatik trat nur hinzu. " Abetz warb in Frankreich mit ebendiesen überparteilichen Qualitäten der AKJ. Grundlage sei das alte Autonomieideal der Wandervogelbewegung, das in der Bündischen Jugend weiterlebe und einen wertvollen Beitrag zum deutsch-französischen und europäischen Einigungsprozeß leisten könne. Abetz, Mouvement de jeunesse et „Volkstum“, in: Notre Temps, 13. 9. 1931, Sp. 78-80.

47 Sohlbergkreis I, S. 2.

48 Abetz, "Denkschrift betr. deutsch-französisches Jugendtreffen auf dem Sohlberg“, pag. 1 f.; AdJb, A 168/1. Prozeß Abetz, 12. 7. 1949, pag. 12; AN, 334 AP 49.

49 Strauss emigrierte nach Hitlers Machtübernahme nach Paris und produzierte Werkzeugmaschinen. Bei Kriegsausbruch meldete er sich zur Fremdenlegion. Während er in Nordafrika diente, beschlagnahmten zunächst französische Behörden, dann die deutschen Besatzer sein Vermögen. Demobilisiert, lebte er mit seiner Familie unter schwierigen Bedingungen in Aix-en-Provence. Im November 1940 bat Weil-Curiel, als Späher de Gaulles in Frankreich unterwegs, Abetz um Hilfe für Strauss. Der Botschafter habe jedoch abgewinkt: „Ce n'est pas que je renie mon amitié, mais je ne peux pas aventurer mon crédit pour de petites choses." Weil-Curiel, Eclipse en France, S. 123, $154 \mathrm{ff} ., 262$. 


\section{Drang nach Osten, Abschottung gegen Westen: Jugendbeziehungen im Schatten von Versailles}

Das deutsch-französische Verhältnis nach 1918 wurde durch einen Gegensatz belastet, der einen für beide Seiten tragfähigen Kompromiß weitgehend ausschloß. Die Siegermacht Frankreich pochte auf eine möglichst exakte Erfüllung des Versailler Vertrags, während sich die unterlegenen Deutschen nach Kräften gegen das "Schand-Diktat" sträubten. Hieraus resultierende Spannungen entluden sich vehement im Ruhrkampf 1923. Erst in der Ära Briand-Stresemann gelangten die Beziehungen in ruhigeres Fahrwasser - „die Befriedung der Gemüter schien [...] eine Zeitlang Wirklichkeit zu sein" 50 . Das politische Tauwetter erleichterte Annäherungsversuche auf wirtschaftlichem und kulturellem Gebiet. Erinnert sei an die deutsch-französische Zusammenarbeit in der Internationalen Rohstahlgemeinschaft, den Handelsvertrag von 1927 und den vom luxemburgischen Großindustriellen Emile Mayrisch ins Leben gerufenen bilateralen Studien- und Informationsausschuß, an dessen Arbeit sich namhafte Wirtschaftsexperten, Politiker und Kulturschaffende beteiligten. In Berlin und Paris bildete sich 1928 eine DeutschFranzösische Gesellschaft, welche die Zeitschriften Deutsch-Französische Rundschau und Revue d'Allemagne herausgab. Im selben Jahr entstand eine Liga für germanische Studien, die in Frankreich dafür warb, die deutsche Sprache zu erlernen und sich mit dem Nachbarland zu befassen. Auch der offizielle Kulturaustausch kam allmählich wieder in Schwung 51 .

Otto Abetz mußte diese Entwicklung ermutigen, selber die Initiative zu ergreifen. Es war ein Unterfangen mit Pioniercharakter, denn Begegnungen zwischen jungen Deutschen und Franzosen waren damals immer noch eine Ausnahme, keineswegs die Regel. Der Krieg hatte die ohnehin bescheidenen Ansätze in den Jugendbeziehungen verschüttet, seine Folgen blockierten eine rasche Wiederaufnahme ${ }^{52}$. Amtliche Stellen in Frankreich rieten zur Vorsicht im Umgang mit einer angeblich friedlosen, nach Revanche dürstenden deutschen Jugend, Reichsbehörden betrachteten eine Abschottung gegen Westen als notwendigen Akt nationaler Selbstachtung und fürchteten unliebsame Verwicklungen. Mißtrauen und Ressentiments beherrschten auch mehr als ein Jahrzehnt nach Kriegsende das Denken vieler. Bezeichnend hierfür ist die Korrespondenz zwischen einem Hamburger Mitglied der Christlichen Pfadfinder und dem Auswärtigen Amt im Frühjahr 1930. Irritiert ob der sich mehrenden Fahrten seiner Kameraden nach Italien und Frankreich, bezweifelte der Briefschreiber ihre „Zweckmäßigkeit“ angesichts der

50 Poidevin/Bariéty, Frankreich und Deutschland, S. 359.

$51 \mathrm{Vgl}$. Lionel Richard, Aspects des relations intellectuelles et universitaires entre la France et l'Allemagne dans les années vingt, in: Bariéty u. a. (Hrsg.), La France et l'Allemagne entre les deux guerres mondiales, bes. S. 117; Meyer-Kalkus, Akademische Mobilität, S. 35 ff., in einer ersten Fassung abgedruckt in Lendemains 17 (1992), Nr. 68. Zum Mayrisch-Komitee L'Huillier, Dialogues franco-allemands, bes. Kap. II und IV. Zur DFG - nicht zu verwechseln mit der 1935 gegründeten Gesellschaft gleichen Namens unter NS-Kuratel (siehe Kap. IV) - Bock, Die Deutsch-Französische Gesellschaft 1926 bis 1934; ders., Die Ligue d'Etudes Germaniques von 1928 bis 1936.

52 Hierzu ausführlich Tiemann, Jugendbeziehungen, S. 20-40. 
aktuellen politischen Lage. Der eingeschaltete Pariser Gesandtschaftsrat Kühn mochte zwar kein „so kategorisches Veto [...] wie etwa gegen Reisen deutscher Regimentsvereine nach französischen Schlachtfeldern" einlegen, bat aber zu berücksichtigen, daß die Jugendbewegung in Frankreich so gut wie unbekannt sei und Gruppen in auffälliger Tracht dort „Kopfschütteln und Befremden“, leicht sogar „Mißdeutungen politischer und wirtschaftlicher Natur" auslösen könnten. Er würde es deshalb begrüßen, wenn „bis auf weiteres“ keine Wanderfahrten deutscher Scouts im Nachbarland stattfänden ${ }^{53}$. Charakteristisch für die verbreitete Abwehrhaltung erscheint auch die Abfuhr, die sich die Arbeitsgemeinschaft Karlsruher Jugendbünde mit einem Zuschußantrag für das Sohlbergtreffen beim Reichsminister für die besetzten Gebiete Treviranus holte. Ganz abgesehen davon, daß der Sohlberg unbesetztes Territorium sei, gehöre „die Förderung deutsch-französischer Jugendaussprachen und ähnlicher Zusammenkünfte [...] unter keinem, wie immer gearteten Gesichtspunkt" zu den Aufgaben seines Ressorts, erwiderte Treviranus barsch ${ }^{54}$.

Vergleichsweise vorurteilsfrei verkehrten in der ersten Nachkriegszeit nur internationalistisch ausgerichtete Parteien und ihre Nachwuchsorganisationen miteinander. Grenzüberschreitende Kontakte und Solidaritätsadressen sollten freilich in erster Linie die Weltrevolution vorantreiben, sie ermangelten einer nationenund jugendspezifischen Orientierung 55 . In den zwanziger Jahren mühten sich Friedensbewegte unterschiedlicher Provenienz um eine Aussöhnung der verfeindeten Nachbarn. Gelegenheit für Zusammenkünfte junger Franzosen mit deutschen Altersgenossen boten insbesondere die „Internationalen Demokratischen Kongresse“ Marc Sangniers (1873-1950). Im August 1926, auf dem Höhepunkt seiner Popularität, versammelte der christliche Sozialreformer in Bierville südlich Paris 5500 Gäste aus 33 Nationen, darunter mehr als 3000 Deutsche. Aber auch unter Berufung auf die Gemeinschaft der Gläubigen ließen sich unvereinbare nationale Positionen nicht dauerhaft überspielen. In den folgenden Jahren „kümmerte der auf Erhaltung der bestehenden europäischen Ordnung ausgerichtete Pazifismus vor sich hin“, während eine zunehmend politisierte deutsche Jugend „immer eindringlicher und unverblümter“ Positionen bezog, „die den Frieden als Funktion der nationalen Wiederaufrichtung definierten" 56 .

Bündische Auslandsaktivitäten konzentrierten sich auf nord- und südosteuropäische Gebiete, in denen deutsche Minderheiten lebten. Statistiken der „Deutschen Freischar" belegen, daß 1929 über 500 ihrer Mitglieder Ostpreußen, Danzig und das Baltikum bereisten, 260 die Tschechoslowakei, 189 Oberschlesien und Polen; rund 190 Jugendliche weilten in Ungarn, Rumänien oder Bulgarien, im-

53 Stellungnahme der Botschaft Paris (handschriftl. redigierter Entwurf) vom 16. 4. 1930, Anfrage ans Auswärtige Amt vom 24. März; PA/AA, R 98887.

54 Der Reichsminister für die besetzten Gebiete an Gustav Mittelstraß (Karlsruhe-Rüppurr), 3. 7. 1930. Mittelstraß, im badischen Unterrichtsministerium tätiger Gymnasiallehrer, hatte per Schreiben vom 5. Juni die AKJ-Bitte um finanzielle Unterstützung wiederholt und befürwortet; ebenda.

55 Tiemann, Jugendbeziehungen, S. 62.

56 Ebenda, S. 77-84, 91. 
merhin 59 im Elsaß, aber nur zwölf in sonstigen Gegenden Frankreichs ${ }^{57}$. Nicht weniger eindeutig ist die Bilanz der „Sächsischen Jungenschaft“, unter Leitung des gebürtigen Dresdeners Hermann Kügler zuerst Herzstück des „WandervogelJungenbundes“, später der „Deutschen Freischar“. Ihre Gruppenfahrten führten in den zwanziger Jahren Hunderte von Jugendlichen fast ausschließlich donauabwärts und zum Landdienst in die Grenzgebiete des deutschen Ostens. Erst 1928 erkor sich ein sechsköpfiges Häuflein Frankreich zum Ziel58. Solidarität mit „Volksdeutschen“ und die Stärkung „bodenständigen Deutschtums durch Besuch aus dem Reiche in seinem Kulturbewußtsein "59 standen im Vordergrund, galten vielen als vaterländische Pflicht. Das verdeutlicht die Politisierung des Volkstumsgedankens nach ungünstigem Kriegsverlauf ${ }^{60}$, mußte allerdings nicht $z$ wingend in nationales Eiferertum ausarten, wie etwa die Auslandsarbeit der „Schlesischen Jungmannschaft" und auch der "Sächsischen Jungenschaft" dokumentiert. „Wir wollen [...] unseren Gesichtskreis nicht durch die Grenzpfähle des Reiches einengen lassen“, postulierte Kügler, „das Wesen des fremden Volkes mit Gefühl und Verstand erfassen, die Beziehung der Völker zueinander kennen und erkennen, die Lage der Deutschen [...] verstehen lernen, [...] Sitten und Gebräuche beachten. "61 Gleichwohl schwebte vielen Bünden ein Schulterschluß Deutschlands und Zwischeneuropas vor, ein durch geographische, historische und nicht zuletzt völkische Bedingtheiten geeinter Wirtschaftsraum, der das Reich aus Abhängigkeiten befreien und dann ein Machtfaktor im internationalen Kräftespiel werden sollte 62 .

Das Interesse der Bündischen an Frankreich war folgerichtig nur schwach entwickelt. In der „Deutschen Freischar“ begrüßte man zwar die durch Locarno geschaffene Atmosphäre der Entspannung, warnte aber vor jeder Übertreibung des Verständigungsgedankens, die den inneren Widerstand der Nation gegen die Versailler Bestimmungen lähmen könnte ${ }^{63}$. Deutlich artikulierte sich Unzufriedenheit über den außenpolitischen Status quo, eine für die Weimarer Republik charakeristische Grundhaltung. Frankreichfahrten, für gewöhnlich gegen massive elterliche und behördliche Bedenken geplant, erschwert durch bürokratische Hindernisse bei der Beschaffung von Visa und Zahlungsmitteln, ähnelten unter solchen Voraussetzungen mutigen Expeditionen in ein verbotenes Land.

Diesen Eindruck vermitteln die Begleitumstände einer sechswöchigen Studienreise, die im Frühjahr 1928 von der "Jungnationalen Vereinigung“" veranstaltet

57 Abgedruckt bei Hardenberg, Bündische Jugend, S. 35.

58 Kneip/Liebs/Zimmermann, Vom Geheimnis bündischer Führung, S. $92 \mathrm{f} ., 106 \mathrm{ff}$.

59 Thierfelder, Der deutsche Reisende im Auslande, S. 525.

$60 \mathrm{Vgl}$. Laqueur, Jugendbewegung, S. 263. Die „Mittelstelle für Jugendgrenzlandarbeit“, 1925 aus der Kooperation zwischen bündischer Jugend und dem „Deutschen Schutzbund für das Grenz- und Auslandsdeutschtum" hervorgegangen und 1930 in „Mittelstelle deutscher Jugend in Europa " umbenannt, trug diesem Aspekt in besonderem Maße Rechnung.

61 Gaurundbrief Küglers zu einer geplanten Ungarnfahrt, 12. 6. 1922; abgedruckt bei Kneip/ Liebs/Zimmermann, Vom Geheimnis, S. $78 \mathrm{f}$.

62 Solche oft nur in Ansätzen vorhandenen Vorstellungen wurden um 1930 besonders in den Schriften des „Tatkreises“ systematisiert. Vgl. Wallwitz, Zur Bedeutung des Volkstumsprinzips, $S, 42 \mathrm{f}$.

63 Hardenberg, Bündische Jugend, S. $84 \mathrm{f}$. 
wurde. Als die 23 Teilnehmer ihre Erlebnisse publizierten, erachteten sie es für ratsam, "mit aller Eindeutigkeit", ja beinahe entschuldigend klarzustellen, daß die Reise "nicht beabsichtigte, Verständigung oder ,rapprochement" in irgendeiner Form zu fördern"; sie sollte „lediglich dazu dienen, politisch interessierten Kreisen der deutschen Jugendbewegung ein unmittelbares Kennenlernen unseres westlichen Nachbarn, der sich bisher als unser schärfster politisch-militärischer Gegner gezeigt hat, zu ermöglichen "64. Hermann Kügler suchte den Eltern eines Vogtländer Oberprimaners einen Frankreichaufenthalt des Sohnes mit dem Argument schmackhaft zu machen, ,im klassischen Land der Höflichkeit und feinen Form " erhalte ihr Filius nützlichen Anschauungsunterricht in Sachen Manieren ${ }^{65}$. Tatsächlich ging es ihm darum, ein seines Erachtens notwendiges erziehungspolitisches Korrektiv zur Balkanarbeit zu schaffen, „die von Südosteuropa her bestimmten Vorstellungen vom Überwert der deutschen Kultur auf das richtige Maß zurück[zu]führen", Interesse an deutsch-französischen Fragen zu wecken und langfristig auf eine Annäherung der alten Gegner hinzuwirken ${ }^{66}$. Auf Vermittlung Pierre Viénots vom Mayrisch-Komitee verbrachten 1928 erstmals sechs junge Sachsen einen vierwöchigen Aufenthalt bei Familien in Caen. Sie wurden von mißtrauischen Einheimischen anfangs als Spione verdächtigt, heischten Respekt ob ihres disziplinierten Arbeitseifers, erschreckten indes ihre Gastgeber, wie sich ein Ortsgeistlicher später entsann, durch ungeniert vorgetragene umfängliche Revisionsforderungen ${ }^{67}$.

64 Diese Erklärung, Tagebuchauszüge von Berliner Fahrtteilnehmern sowie ein abschließendes Fazit - „nur ganz fest geschlossene Gruppen mit absolut klarer Führung werden das Wagnis unternehmen können" - sind abgedruckt in: Sohlbergkreis II (Dezember 1931), S. $13 \mathrm{ff}$.

65 Zit. bei Kneip u. a., Vom Geheimnis, S. 111.

$66 \mathrm{Vgl}$. Küglers Angaben, ebenda, S. $106 \mathrm{ff}$.

67 Reisebericht und Zeugnis des Priesters abgedruckt ebenda, S. 107-111. Pierre Viénot (1897-1944) gilt unter den französischen Intellektuellen der Zwischenkriegszeit, die sich eingehend mit Deutschland beschäftigten, als "der große Unbekannte ${ }^{\star}$ (Hans Manfred Bock). Der Juristensohn, 1917 als Kriegsfreiwilliger schwer verwundet, zu Beginn der zwanziger Jahre im persönlichen Stab Marschall Lyauteys in Marokko und von diesem in der Folge protegiert, während eines Studienaufenthalts in Bonn 1923 für das schwierige deutsch-französische Verhältnis und wechselseitige Fehldeutungen sensibilisiert, hatte maßgeblichen Anteil am Zustandekommen des von Emile Mayrisch geleiteten Deutschfranzösischen Studienkomitees/Comité franco-allemand d'information et de documentation, dessen Berliner Büro er von 1926 bis 1930 leitete. Danach startete er eine politische Karriere, war 1936/37 Unterstaatssekretär im französischen Außenministerium und setzte sich für Emigranten des ,Dritten Reiches' ein. 1940 befürwortete er eine Fortsetzung des Kampfes von Nordafrika aus, 1943 wurde er enger Mitarbeiter de Gaulles. Seinen Lebensweg schildert im Lichte neuer Quellenfunde Bock, „Connaître l'Allemagne et la reconnaître“. 


\section{Wider den Geist der Unbeweglichkeit: Abetz' Partner Jean Luchaire}

Vor diesem Hintergrund erscheint Otto Abetz' Fühlungnahme mit der jungen Generation Frankreichs im Frühjahr 1930 als außergewöhnlicher, keinesfalls alltäglicher Schritt. In der Woche nach Ostern knüpfen er und sein Begleiter in Paris die ersten, entscheidenden Kontakte ${ }^{68}$. Im Quartier Latin treffen sie Robert Lange, Gründungsmitglied einer Internationalen Studentenvereinigung zur Unterstützung des Völkerbundes. Lange verweist die Deutschen an Cecil Mardrus, mit einigen Kommilitonen von der Sorbonne soeben dabei, ein „Groupement universitaire franco-allemand" aus der Taufe zu heben, das sich für den Frieden und verstärkten Kulturaustausch engagieren will69. Mardrus genießt Sympathien bei Redakteuren der Zeitschrift Notre Temps, deren Herausgeber Jean Luchaire Abetz ebenfalls aufsucht - eine Begegnung, die sich als „besonderer Glücksfall“70 für das Gelingen seiner Mission erweist und weitreichende Folgen für beide hat. Luchaire plaudert gerade mit seinem Mitarbeiter Jacques Nels, als die Sekretärin meldet: „Un jeune Allemand qui vient d'arriver désire vous voir." Herein tritt ein kräftiger, etwas vierschrötig wirkender Mann in zünftiger Fahrtkleidung, mit weißen Strümpfen und kurzen Hosen, wie Nels belustigt registriert. Er stellt sich vor: „Professeur de dessin à Karlsruhe, Otto Abetz."71 Schnell ist das Eis gebrochen und Luchaire für das Projekt eines deutsch-französischen Treffens gewonnen. Abends macht er Abetz mit Kollegen bekannt, die in einem kleinen Bistro am Seine-Ufer speisen. Anrührend, in holprigem Französisch erzählt der Gast, wie sehr er wünsche, daß die alte, verheerende Feindschaft endlich begraben werde, und daß er sich von seinem bescheidenen Gehalt, von welchem er die Mutter unterstützen muß, regelmäßig französische Zeitungen und Magazine kauft. Man hebt die Gläser und trinkt auf bessere Zeiten ${ }^{72}$.

Jean Luchaire rührte in der Folge kräfrig die Werbetrommel für das Sohlbergtreffen und koordinierte gemeinsam mit dem "Groupement universitaire“, das Anmeldungen entgegennahm, die Vorbereitungen auf französischer Seite ${ }^{73}$. Sein

68 "Curriculum vitae d'Otto Abetz“, pag. 3; AN, F 7/15331.

69 Die Deutsch-Französische Rundschau berichtete über die Neugründung im Juniheft 1930, S. 518 f.; vgl. Unteutsch, Sohlbergkreis, S. 51 f.

70 Epting, Das Schicksal der briandistischen Generation, S. 17.

71 Nels, Fragments, S. 114f. Irrig die Behauptung, Abetz habe Luchaire schon 1928 kennengelernt; vgl. Sternfeld, Ambassador Abetz, in: Contemporary Review, CLXII (August 1942), S. 85.

72 So bezeugt vom späteren Paris-Soir-Chefredakteur und Exilanten Pierre Lazareff, Dernière édition, S. $67 \mathrm{ff}$. Abetz vervollkommnete seine Sprachkenntnisse laufend, schon bald sprach er Französisch fast fehlerfrei, wie Weil-Curiel anerkennend vermerkt: „Otto était déjà arrivé à une extraordinaire maîtrise du français. Nourri des meilleurs auteurs contemporains, il disposait d'un vocabulaire inépuisable et parlait un langage raffiné qui traduisait toutes les nuances de sa pensée, qui était parfois subtile“. Weil-Curiel, Eclipse en France, S. 125. Die Heirat mit einer Französin, Luchaires Sekretärin, im Sommer 1932 tat ein übriges.

73 Vgl. Notre Temps, 29. 6. 1930, letzte Seite, mit Einzelheiten zu Kosten, Anreise und Programm. 
weiterer Lebensweg, vom gefeierten journalistischen Ausnahmetalent zum geächteten Kollaborateur, ist eng an Abetz' Werdegang gekoppelt, der seiner bedingungslosen Unterstützung stets gewiß sein durfte. Umgekehrt hat die überwältigende Resonanz, die der Karlsruher Initiative im Umfeld von Notre Temps beschieden war, Abetz endgültig und über alle politischen Wechselfälle hinweg auf das Problem der deutsch-französischen Annäherung fixiert - Grund genug, das Profil der Zeitschrift und ihres Herausgebers zu beleuchten.

Jean Louis Gabriel Luchaire, Sproß einer angesehenen Gelehrtenfamilie, wurde am 21. Juli 1901 in Siena geboren ${ }^{74}$. Sein Vater war Professor für italienische Literatur an den Universitäten Grenoble und Lyon, später Direktor der Französischen Institute in Florenz, Mailand und Neapel. Jean lebte von 1908 bis nach dem Krieg mit Unterbrechungen in Italien, in einem Umfeld, das dem Heranwachsenden vielfältige geistige Anregungen bot. Ein Jura- und Philosophiestudium gab er nach kurzer Zeit auf, desgleichen einen kleinen Posten in der staatlichen Kunstverwaltung, den ihm Edouard Herriot, ein Freund seiner Mutter, vermittelt hatte. Kaum 20 Jahre alt und verheiratet mit einer Enkelin des Malers Albert Besnard, schlug er, seinen Neigungen folgend, eine journalistische Laufbahn ein. Er spezialisierte sich auf außenpolitische Themen. Im Kollegenkreis galt er als außergewöhnlich begabt, als ein Mann, der das Metier ungeachtet seiner Jugend beherrschte, hochintelligent, mitreißend, ebenso gewandt wie leidenschaftlich in der Argumentation ${ }^{75}$.

Der Erste Weltkrieg hat Luchaire, ebenso wie Abetz, entscheidend beeinflußt und bemerkenswertes Engagement für Pazifismus und Völkerverständigung geweckt. In seinem 1929 erschienenen, auch in Deutschland beachteten Buch Une génération réaliste schildert er, wie die Ausnahmesituation der Jahre 1914 bis 1918 Klassenunterschiede und politische Gegensätze in den Schützengräben und an der Heimatfront verwischte, wie der quälende Anblick verstümmelter, sterbender Soldaten nicht nur ihn, der in einem Lazarett bei Grenoble aushalf, sondern unzählige Heranwachsende zu Kriegsgegnern formte - Erfahrungen, die Altersgenossen in allen kriegführenden Staaten gemacht hätten und die mithin den gemeinsamen Ausgangspunkt seiner Generation markierten ${ }^{76}$. Groß sei die Hoffnung dieser Jugend auf eine gerechtere Weltordnung gewesen, als die Waffen endlich schwiegen, noch viel größer jedoch die Enttäuschung über restaurative, verhängnisvolle Mechanismen erneut in Gang setzende Tendenzen: „La fraternité

74 Die biographischen Angaben stützen sich auf das Protokoll des Luchaire-Prozesses vom Januar 1946, Les procès de collaboration, S. $353 \mathrm{ff}$., $359 \mathrm{ff}$., $558 \mathrm{ff}$.; präzise Erinnerungen des frühen Weggefährten Jacques Nels, Fragments, bes. S. 71ff., 83-120; und die Studie von Lévy, Les Nouveaux Temps, S. 11-17. Vgl. Unteutsch, Sohlbergkreis, S. 50 f.

75 „Il nous dépassait tous en précocité, en talent, en charme, en générosité. Hélas aussi en imprudences. “Jouvenel, Voyageur, S. 81. Ähnlich zwiespältig das Urteil von Nels, der Energie und Überzeugungskraft rühmt, nicht ohne anzufügen: "Jean était un séducteur. ${ }^{\text {" Frag- }}$ ments, S. 85, 109.

76 Une génération réaliste (1929), S. 9 ff. Zur Genese und mentalen Prägung dieser „Kriegsgeneration" ders., Eine realistische Generation, in: Nord und Süd, 1929, S. 429-441. Die Lektüre des Buches lenkte Abetz' Aufmerksamkeit auf Luchaire und gab den Anstoß, ihn aufzusuchen; "Curriculum vitae“, pag. 3. Luchaire habe „zahlreiche, auch für das junge Deutschland gültige Gedanken“ vertreten; Abetz, Das offene Problem, S. 28. 
internationale attendue faisait place à des haines nouvelles. Et à la fraternité intérieure on substituait la lutte sociale. "77 Verbittert, so Luchaires Beobachtung, hätten sich daraufhin viele eine Zeitlang vom politischen Tagesgeschehen zurückgezogen ${ }^{78}$, um dann, zu „Realisten“ gereift, den Kampf für eine evolutionäre Umgestaltung der Verhältnisse aufzunehmen. Ihn selber hielt es nicht, seinen Abscheu vor Krieg und Militarismus, seine Empörung ob des ausgebliebenen Wandels im Zusammenleben der Völker, der Wiederkehr von Grenzbarrieren und Geheimdiplomatie kundzutun. Auch an den Pariser Vorortverträgen, die künftige Konflikte programmierten, übte er scharfe Kritik. „La guerre“, formulierte er 1919 für ein Manifest, "nous a rendu le monde ancien empiré, désordonné, croulant de toutes parts; elle nous a rendu des hommes anciens, impuissants, fatigués, découragés par l'épreuve inutile. "79 Remedur erwartete Luchaire von einer Internationalen der Jugend, die - über allen Nationen, Ideologien und Parteien stehend - ein stabiles, einiges Europa verwirklichen und gleichsam den Kitt dafür bilden sollte ${ }^{80}$. Für diese Idee warb er zu Beginn der zwanziger Jahre in mehreren gemeinsam mit Freunden lancierten Zeitschriften, L'Effort, La Jeune Europe und Vita, die zum vertieften Studium internationaler und gesellschaftspolitischer Fragen einluden ${ }^{81}$, ihr Erscheinen aber allesamt aus Geldmangel bald wieder einstellten. L'Effort war Organ der „Union internationale de jeunes pour l'étude des questions sociales“, einer wegen akuter Finanznot kurzlebigen Eigenschöpfung. Danach engagierte sich Luchaire vorübergehend bei der „Fédération des jeunesses laïques et républicaines", einer den Radikalsozialisten nahestehenden Organisation, mit der es wegen inhaltlicher Differenzen zum Bruch $\mathrm{kam}^{82}$. Seinen Lebensunterhalt verdiente er, schon damals einen fatalen Hang zum leichtfertigen Umgang mit Geld offenbarend, Wurzel späterer sprichwörtlicher Bestechlichkeit ${ }^{83}$, als Kolumnist bekannter linksgerichteter Blätter wie L'Ere Nouvelle, Le Petit Parisien und La Volonté.

1927 trat er den Radicaux, denen er Überalterung, verkrustete Strukturen und eine zu einseitige Beschäftigung mit innenpolitischen Themen vorwarf, nach einigem Zögern bei. Seine Ideen versuchte er dort in einem Zirkel überwiegend junger, aktionshungriger Intellektueller durchzusetzen, die nach dem Scheitern des Cartel des gauches eine stetig an Einfluß gewinnende Reformbewegung in der Radikalsozialistischen Partei und ihrem politischen Gravitationsfeld bildeten, Cail-

77 Luchaire, Une génération réaliste, S. 37.

78 Die hier angedeutete Haltung der französischen Jugend in der ersten Nachkriegszeit unterschied sich offenbar nicht wesentlich von der in der deutschen Jugendbewegung vorherrschenden Stimmung - so Luise Fick, Jugendbewegung, S. 138: „Um das Jahr 1921 setzte fast überall eine große Enttäuschungswelle ein. Wer von der Mühle der großen Organisationen nicht zermahlen war, wandte [...] dem politischen Tageskampf den Rücken, der nach wie vor von Klassen, Parteien, Interessenpolitik und Wirtschaftsegoismus bestimmt war".

79 Zit. im Luchaire-Prozeß, S. 559.

${ }^{80}$ Luchaire, Une génération réaliste, $\mathrm{S} .75 \mathrm{f}$.

81 Vgl. "Le Manifest de L'Effort" vom Juni 1920, ebenda, Anhang II.

82 Nels, Fragments, S. $91 \mathrm{ff}$.

83 Ebenda, S. 84, 189 f.; Jouvenel, Voyageur, S. 83 f.; über den verschwenderischen Lebensstil ihrer Eltern auch die älteste Tochter Corinne Luchaire, Ma drôle de vie, S. 27. 
laux und Daladier nahestanden und unter dem Namen "Jeunes Turcs" bekannt wurden ${ }^{84}$. Um ihnen ein öffentliches Forum zu verschaffen, gab Luchaire zusammen mit dem Caillaux-Adepten und Vizepräsidenten der Radicaux, Emile Roche, eine neue Zeitschrift heraus: Notre Temps. Sie erschien von Juni 1927 an zunächst monatlich, von Redakteuren und Sympathisanten finanziert, mit einer Auflage von 3000 Exemplaren. Im Mittelpunkt standen neben literarischen Themen vor allem Visionen eines europäischen Zusammenschlusses, der als Vorbedingung für einen dauerhaften Frieden gesehen wurde. Diese Haltung, die auch im zeitweise verwendeten Untertitel Revue des nowvelles générations européennes zum Ausdruck kam, harmonierte mit der Politik Briands, der nach den Wahlen 1928 ins französische Außenministerium zurückkehrte. Briand zog Luchaire ins Vertrauen, nahm ihn zu internationalen Konferenzen mit und förderte Notre Temps auch materiell. Aus einem Sonderfonds des Quai d'Orsay flossen anfänglich 10000 , dann 20000 Francs pro Monat, die der rasch an Reputation gewinnenden Zeitschrift ein wöchentliches Erscheinen mit erweitertem Umfang ermöglichten. Die Auflage kletterte bis 1930 auf etwa 5000 Exemplare 85 .

Das Magazin, so seine Herausgeber, „donnait au public une synthèse des désirs et des caractéristiques de notre jeunesse" ${ }^{\text {"86 }}$. Tatsächlich artikulierte sich in den ersten Jahrgängen eine Vielzahl junger, aufstrebender Intellektueller, ein von „Jungtürken" und Sympathisanten der Sozialistischen Partei gebildeter Freundeskreis, der 1933/34 nicht zuletzt über die Frage der Haltung zu Hitler-Deutschland auseinanderfiel und dessen Mitglieder als Publizisten, Künstler und Politiker, als Kollaborateure der deutschen Besatzungsmacht oder im Widerstand von sich reden machen sollten. Zum festen Mitarbeiterstamm um Luchaire und Chefredakteur Jacques Chabannes zählten zu Beginn der dreißiger Jahre: Jacques Nels, ein naturalisierter Franzose polnisch-russischer Herkunft, der als Redaktionssekretär fungierte, 1935 zur linken Wochenzeitung Vendredi wechselte und als Romancier und Theaterfachmann bekannt wurde; Pierre Brossolette, Leiter des Ressorts Außenpolitik, als Résistancekämpfer hingerichtet, der Notre Temps ebenso wie Chabannes, Nels und andere den Rücken kehrte, weil er eine Verständigung mit Hitler für ausgeschlossen hielt und dem unter nationalsozialistischen Vorzeichen fortgesetzten Werben von Abetz mißtraute; Guy Crouzet, langjähriger Literaturkritiker und von Herbst 1940 an mit stark antisemitischem Einschlag dem Kollaborationsblatt Les Nouveaux Temps verschrieben; Bertrand de Jouvenel, Senatorensohn und neoliberaler wirtschaftspolitischer Vordenker der "Jeunes Turcs“; RaymondRaoul Lambert, Völkerbundexperte und "Chef du service franco-allemand“, der nach $1933 \mathrm{im}$ „Comité d'assistance aux réfugiés d'Allemagne“ saß. Herausragende

${ }^{84}$ Den Ausdruck prägten politische Gegner in ironischer Absicht, in Anspielung auf die jungen Revolutionäre im alten Osmanischen Reich. Über Bedeutung und Ziele der "Jeunes Turcs“ Berstein, Histoire du Parti Radical, Bd. II, S. 94-122; Nordmann, Histoire des Radicaux, S. $236 \mathrm{ff}$; Andreu, Les idées politiques, in: ders., Révoltes de l'esprit, S. 175-189; du Réau, Daladier, S. $53 \mathrm{ff}$.

85 Zahlenangaben nach Les procès de collaboration, S. 363, und Lévy, Les Nouveaux Temps, S. 16. Über die freundschaftlichen Bande zwischen alterndem Staatsmann und jugendlichem Bewunderer, die eine Passion für Kriminalromane teilten, Nels, Fragments, S. 114.

86 Luchaire, Une génération réaliste, S. 108. 
Kolumnisten waren ferner der zeitweilige Generalsekretär der Radicaux und Daladier-Vertraute Jacques Kayser, der am Anfang seiner politischen Karriere stehende Pierre Mendès-France und sein Jura-Kommilitone André Weil-Curiel von der "Ligue d'action universitaire républicaine et socialiste“, Theaterleute wie Marcel Achard und die Schriftsteller Jean Prévost, Claude Aveline und Julien Green; der Abgeordnete Jean Montigny, der künftige Minister Pierre Cot, Paul Marion, dereinst Generalsekretär für Propaganda des Vichy-Regimes, schließlich Bernard Lecache, Antirassist und Gründungsmitglied der "Ligue internationale contre l'antisémitisme" 87.

Luchaire selbst erwies sich als kongenialer Partner, der sich zum Teil aus genau denselben Motiven der Verständigung verschrieben hatte wie Abetz und dem Deutschen auch hinsichtlich persönlicher Stärken und Schwächen wesensverwandt war. Beide, von jugendlicher Unbekümmertheit und gewinnendem Auftreten, schienen für erfolgreiche Mittlerrollen prädestiniert und verfügten über beachtliche rhetorische und propagandistische Fähigkeiten; ihre Freundschaft strahlte auf Gleichgesinnte aus. Beiden kam nach Beginn der Nazi-Diktatur, während sie an hehren Zielen festzuhalten meinten, der Sinn für Realität und Redlichkeit allmählich abhanden; ihre Ideale und ihre persönliche Integrität glaubten sie selbst dann noch gewahrt, als sie längst materiellen Verlockungen erlegen und in verbrecherische Machenschaften verstrickt waren. Luchaire, der unter Abetz' Patronage ein Hauptorgan der Kollaborationspresse (Les Nouveaux Temps) leitete ${ }^{88}$, beteuerte noch 1946 vor den Schranken eines Pariser Gerichts, das ihn zum Tode verurteilte, daß er - „même à l'heure actuelle“ - an Abetz' Aufrichtigkeit und Liebe zu Frankreich glaube ${ }^{89}$. Der wiederum kommentierte die Hinrichtung des Freundes mit der bissigen Bemerkung, Europa gehe nicht eben haushälterisch mit seinen Eliten um 90 .

Hinsichtlich mancher Ziele und Lösungsstrategien keineswegs konform, einte die "Jeunes Turcs" der Wille zum Bruch mit Überkommenem. Insofern waren sie Teil jenes Phänomens revoltierender, sich nonkonformistisch gebärdender junger Franzosen, die um 1930 gegen die herrschenden politischen und gesellschaftlichen Verhältnisse aufbegehrten ${ }^{91}$. Überzeugt, daß die bestehende Ordnung künftigen Herausforderungen nicht gewachsen sei, riefen sie zu Neubesinnung und Erneuerung auf, forderten eine vom antiquierten Wertesystem der Väter unbelastete Auseinandersetzung mit der Gegenwart. Die "Jungtürken“ bemängelten Schwachstellen im politischen System und wollten die ,Dritte Republik' durch Verfassungs- und Verwaltungsreformen modernisieren. Sozial unverträgliche Wucherungen des Kapitalismus sollten durch eine moderate, am Gemeinwohl orientierte staatliche Lenkung der Wirtschaft beseitigt werden. Leidenschaftliche Pazifisten

87 Vgl. Claude Lévy, Autour de Jean Luchaire: le cercle éclaté de Notre Temps, in: Bock u.a. (Hrsg.), Entre Locarno et Vichy, Bd. I, S. 121-130; du Réau, Daladier, S. 68ff.; Nels, Fragments, S. 110 ff.; Berstein, Parti Radical, II, S. 101; Gilberte Brossolette/J.-M. Fitère, Il s'appelait Pierre Brossolette, S. $49 \mathrm{ff}$.

88 Grundlegend hierzu Lévy, Les Nouveaux Temps.

${ }^{89}$ Les procès de collaboration, $S .364$.

90 Abetz, Das offene Problem, S. 29.

91 Grundlegend hierzu Loubet del Bayle, Les non-conformistes des années 30. 
und Europäer, unterstützten sie den Völkerbund und erträumten sich eine europäische Föderation auf der Basis einer deutsch-französischen Aussöhnung. Genau in diese Richtung mußte sich ihrer Meinung nach die Pariser Diplomatie bewegen; konziliante Gesten wie eine baldige Räumung des Rheinlandes und eine rasche Regelung der Saarfrage sollten den Entspannungsprozeß beschleunigen. „Nous étions une génération raisonnable, soucieuse de l'avenir, souhaitant que ce fût un avenir de réconciliation et de paix, et un avenir de progrès économique et social“, erläuterte Bertrand de Jouvenel92.

Unter solchen Prämissen war Abetz und Bentmann ein herzlicher Empfang gewiß. Die Notre Temps-Equipe hatte bereits ein waches Auge auf Deutschland. Im Sommer 1928 versuchte eine Artikelserie mit dem Titel „A la recherche de l'Allemagne" aktuelle politische und geistige Strömungen jenseits des Rheins auszuloten, wobei die Jugendbewegung als wichtige Trägerin innovativen Ideenguts eingestuft wurde93. Daß es zwischen "Jungtürken“ und Karlsruher Kundschaftern „funkte“, stützt im übrigen die Annahme eines grenzübergreifenden, identitätstiftenden Generationsbewußtseins der Kriegsjugend. Die Suche nach neuen Wegen war seither zwar unterschiedlich verlaufen - während ein Luchaire schon früh publizistische Breitenwirkung entfaltete und seine Ziele im Windschatten einer arrivierten politischen Partei verfolgte, hatten seine jugendbewegten deutschen Gesprächspartner ihre Gemeinschaftsideale bevorzugt in kleinen autonomistischen Gruppen gepflegt, freilich in der Absicht, ihnen eines Tages in der Gesellschaft Geltung zu verschaffen. Unbeschadet der beträchtlich voneinander abweichenden Herkunft und Lebensstile aber wurde der Brückenschlag mühelos vollzogen, dank bemerkenswerter Stimmigkeiten im Lebensgefühl. Die meisten Mitarbeiter von Notre Temps waren wie ihre neuen Freunde aus Baden um die Jahrhundertwende geboren und in einer Zeit gewaltiger Umbrüche aufgewachsen. Hüben wie drüben hatte man die Schrecken des Krieges verinnerlicht; man spürte die Dringlichkeit veränderter Grundlagen in den internationalen Beziehungen, rieb sich am Beharrungsvermögen der Altvorderen und betonte den Eigenwert der Jugend wie ihr Recht auf verantwortliche Mitgestaltung der Lebensverhältnisse. Es gelte den „Geist der Unbeweglichkeit“, die unseligen „Dogmen, Formeln und Methoden einer vergangenen Epoche" zu bekämpfen, postulierte Luchaire zum Jahreswechsel 1929/3094. „Unsere heutigen Politiker gehören jener Generation an, der wir den Krieg verdanken", wird Abetz seinerseits mit einem

92 Jouvenel, Voyageur, S. 78. Das Ideengut der „Jeunes Turcs“ findet sich in einem „Programme des Jeunes-Radicaux “ vom März 1929, in einer von der Librairie Valois 1928/29 publizierten Buchreihe (in der Luchaires Une génération réaliste, L'Economie dirigée von B. de Jouvenel und ein Werk von Gaston Riou mit dem programmatischen Titel Europe, ma patrie erschienen) sowie in den 1927 bis 1929 unter jeweils maßgeblichem Anteil von Emile Roche lancierten Zeitungen Notre Temps, La Voix und La République. Eine konzise Zusammenfassung bei Berstein, Parti Radical.

93 Vgl. die Notre Temps-Ausgaben vom Juni bis Oktober 1928, zu Geschichte und Gliederungen der Jugendbewegung im besonderen das Juli-Heft, S. 24-29. Deutschlands junge Generation und ihr Wollen waren in der zweiten Hälfte der zwanziger Jahre wiederholt Untersuchungsgegenstand französischer Autoren, vor allem in der Revue d'Allemagne. Einzelheiten bei Tiemann, Jugendbeziehungen, S. $108 \mathrm{ff}$.

94 Zit. von Hardenberg, Bündische Jugend, S. 98. 
Beitrag für ein christlich-soziales Stuttgarter Magazin zitiert. „Nur die Entschlossenheit junger Menschen - junger Menschen, die aufrichtig für eine Beseitigung der alten Fehler und Ungerechtigkeiten arbeiten und den Grundstein für eine bessere, friedliche Welt legen wollen - kann eine echte Zusammenarbeit zwischen Deutschland und Frankreich begründen. ${ }^{~} 95$ Die konkreten Bedingungen und Hindernisse für einen Ausgleich wurden im ersten freudigen Überschwang, im Nachbarland auf Gleichgesinnte gestoßen zu sein, offenbar nicht näher erörtert. Spätestens im darauffolgenden Jahr 1931 erschwerten dann solche Fragen den begonnenen Dialog und sorgten für allgemeine Ernüchterung.

Etliche der neugewonnenen Pariser Bekannten, die in enger Beziehung zur Radikalsozialistischen Partei standen, attestierten dem jungen Abetz einen ähnlichen politischen Zuschnitt. Einzig Bertrand de Jouvenel reihte ihn schon für die Zeit vor 1933 in das Lager der Rechten ein und schildert einen temperamentvollen Ausfall des Karlsruhers gegen die deutsche Linke, die der "unwiderstehlichen Kraft" des neuerwachten Nationalismus nichts entgegenzusetzen hätte, weshalb die Zukunft der deutsch-französischen Annäherung in verstärkten Kontakten zu rechtsgerichteten jungen Deutschen läge ${ }^{96}$. Jacques Chabannes indessen ging davon aus, daß Abetz SPD-Mitglied sei97, Alfred Silbert vom „Groupement universitaire franco-allemand" will ihn ermutigt haben, aufgrund seiner politischen Ambitionen ebendieser Partei beizutreten ${ }^{98}$. Die Journalisten Pierre Lazareff und Edouard Lavergne porträtierten ihn als Vertreter des katholischen Flügels ${ }^{99}$, André Weil-Curiel urteilte vager, er sei zu Sohlbergzeiten wie alle seine Landsleute gegen den Versailler Vertrag, ansonsten aber politisch nicht festgelegt gewe$\operatorname{sen}^{100}$. Auch Franzosen, die Abetz' Bekanntschaft erst später machten, neigten dazu, ihn für einen ursprünglich aufrechten Pazifisten und Demokraten zu halten, so André François-Poncet und der Schriftsteller Jules Romains, dessen Erinnerungen zufolge sich Abetz für Deutschland ein gänzlich anderes Regime wünschte als das nationalsozialistische ${ }^{101}$. Diese Überlieferungen fanden Eingang in die zeitgeschichtliche Forschungsliteratur, etwa bei Lévy, für den ein sozialdemokratischer Hintergrund Abetz' außer Frage zu stehen scheint ${ }^{102}$, oder bei

95 Zit. nach Lazareff, Otto Abetz, Hitler's Termite, in: Current History, 23. 1. 1941, S. 17 (ohne nähere Quellenangabe, Rückübers. durch den Verfasser).

96 Jouvenel, Voyageur, S. 200, in fast wörtlicher Übereinstimmung mit einem Beitrag für Candide während der Abetz-Affäre 1939, zit. von René Naegelen, L'Ascension d'Otto Abetz, in: Justice, 21. 7. 1939.

97 Mündliches Zeugnis bei Brossolette, Pierre Brossolette, S. 53 („un social-démocrate").

98 „Il songeait à faire de la politique; nous étions nombreux à l'encourager [...] à entrer au parti social-démocrate qui était encore le grand parti allemand de l'époque." Zeugenaussage Silberts im Abetz-Prozeß, 19. 7. 1949, pag. 55; AN, 334 AP 49.

99 Lazareff, Dernière édition, S. 267 („l'ancien démocrate chrétien“); Lavergne, J'ai connu Otto Abetz, in: Le Petit Parisien, 28. 7. 1939: „Dans sa première incarnation, Abetz fut [...] le chef des Jeunesses catholiques du duché de Bade."

100 Weil-Curiel, Eclipse en France, S. $123 \mathrm{f}$.

101 Schriftliche, im Abetz-Prozeß verlesene Erklärung Poncets, 12. 7. 1949, pag. 34; AN, 334 AP 49. Romains, Sept mystères, S. 225.

102 Lévy, Les Nouveaux Temps, S. 18 („Abetz, dont les sympathies social-démocrates étaient connues"). 
Wallace, der christlich-soziale Bindungen hervorhebt ${ }^{103}$. Eine Agenturmeldung aus dem Jahr 1954 wiederum besagt, Abetz habe der linksliberalen, zur Weimarer Koalition zählenden Deutschen Demokratischen Partei angehört ${ }^{104}$, was mit der Nachkriegskarriere seines Mitarbeiters und Rechtsanwalts Ernst Achenbach bei der F.D.P. zusammenhängen mag, allerdings ebensowenig zu belegen ist oder als glaubwürdiges Ergebnis fundierter Recherche anmutet wie die anderen Angaben über seine anfängliche parteipolitische Orientierung. Er selber schwieg dazu, hat die Behauptungen weder kommentiert noch dementiert ${ }^{105}$. Daß er das Image des republiktreuen Demokraten zumindest bereitwillig akzeptierte, von einem bestimmten Zeitpunkt an vielleicht bewußt pflegte, weil es geeignet war, französisches Vertrauen in seine Person zu stärken, liegt angesichts der ihm eigenen taktischen Wendigkeit nahe. Nicht von ungefähr betonte er den Stellenwert der Linksparteien für das politische Leben und die öffentliche Meinung in Frankreich. Nützliche Verbindungen in dieses Milieu unterhielt er später selbst gegen den erklärten Widerstand strammer Nationalsozialisten, was seine Sachkenntnis nur unterstreicht. Die Tatsache, daß die Arbeitsgemeinschaft Karlsruher Jugendbünde Gruppierungen jedweder Couleur vereinte, konnte französische Gesprächspartner im übrigen ebenfalls verleiten, den sympathischen Badener ihren jeweiligen Präferenzen entsprechend zu verorten. So besehen hat die von der AKJ praktizierte Überparteilichkeit die Ungereimtheiten in diesem Punkt seiner Biographie gefördert, Abetz anderseits sicherlich geholfen, binnen kurzem Zugang zu unterschiedlichsten politischen und ideologischen Strömungen im Nachbarland zu finden, ein Kapital, das sich Schirach und Ribbentrop zunutze machten.

Außer Zweifel steht die in ihrer Bedeutung kaum zu überschätzende Langzeitwirkung der Ostern 1930 gleich beim ersten Anlauf geknüpften Kontakte. Luchaire, Crouzet, de Jouvenel und andere blieben auf Jahre hinaus, über die einschneidende Zäsur der nationalsozialistischen ,Machtergreifung' hinweg, zum Teil selbst während der deutschen Besatzung willige Informanten und hilfreiche, manipulierbare Mittelsmänner, die Türen öffneten und das Meinungsklima im prodeutschen Sinn beeinflußten. Die Begegnung in Luchaires weißgetünchtem Büro wurde so zum Ausgangspunkt eines sich rasch verästelnden Beziehungsgeflechts und der propagandistischen Durchschlagskraft, die Abetz nach 1933 in Diensten des Hitler-Regimes zu entwickeln vermochte.

103 Wallace, Otto Abetz, S. 16.

104 Interpress Hamburg, 9. 4. 1954.

105 Auch sein späterer Strafverteidiger René Floriot nannte ihn unwidersprochen einen "homme de gauche“, weswegen er 1933 seines Postens als AKJ-Vorsitzender enthoben worden sei; Les procès de collaboration, S. 580 . 


\section{5. „Vermarktung einer Kreation“? Vom Sohlbergtreffen zum Sohlbergkreis}

In euphorischer Erwartung verbreiteten Luchaire und Mardrus die Kunde vom bevorstehenden Treffen auf dem Sohlberg. Es sei „das erste seiner Art", meldete Notre Temps; aus eigenem Antrieb wünschten Jugendliche aus Baden sich offen und ernsthaft mit französischen Altersgenossen auszutauschen ${ }^{106}$. Interesse zeigten unter anderem die 1929 in enger Anlehnung an die Deutsch-Französische Gesellschaft entstandene „Ligue d'Etudes Germaniques“, das den Radicaux nahestehende "Groupement universitaire pour la Société des Nations", die Zeitschrift La Jeune République, gegründet von Marc Sangnier, ferner mehrere politische Jugendorganisationen „vom linken Flügel der Sozialdemokratie bis zur Gefolgschaft der monarchistischen Action Française"107. Angeführt von Notre TempsRedakteuren und Vertretern des "Groupement universitaire franco-allemand", fuhr schließlich eine bunt zusammengewürfelte, etwa 60köpfige Delegation in den Schwarzwald.

Die Karlsruher Gastgeber warben für ihr Vorhaben mit einem zweisprachig abgefaßten Einladungsschreiben, illustriert mit Bildern der Jugendherberge, des Kirchenaltars zu Lautenbach und einem Panorama „Blick vom Sohlberg auf die Rheinebene". Die vierseitige Broschüre, in nicht bekannter Anzahl verteilt, enthielt alles Wissenswerte über Anfahrtsmöglichkeiten, Programm und Aufenthaltskosten (Teilnahmegebühr 5 RM, Verpflegung pro Tag 1,25 RM, Übernachten im Schlafsaal 0,30 RM, im Einzelzimmer 0,60 RM, im Zelt 0,15 RM) ${ }^{108}$. Es gelang Abetz, die offiziöse, soeben eröffnete Deutsche Akademisch-Pädagogische Vermittlungsstelle in Frankreich (DAPV), Vorläuferin der DAAD-Zweigstelle Paris, für sein Projekt zu begeistern. DAPV-Leiter Hans Göttling setzte sich mit Erfolg dafür ein, daß den französischen Besuchern kostenlose Visa ausgestellt wurden. „Ich glaube, daß die Angelegenheit wirklich wert ist, daß man sie in dieser Weise unterstützt “", empfahl er dem Auswärtigen Amt unter Hinweis auf ein beigefügtes Einladungsschreiben. Das Vorhaben mache einen „sehr guten Eindruck, und wenn es einigermaßen geht, werde ich selbst hinfahren" ${ }^{109}$. Heinz Dähnhardt, Vorsitzender des mehr als 3,5 Millionen Mitglieder zählenden Reichsausschusses der deutschen Jugendverbände, nahm gleichfalls Notiz und sagte sein Mitwirken

106 Notre Temps, 29.6. 1930. Während eines SS-Ehrengerichtsverfahrens 1937/38 (siehe Kap. VI) behauptete Abetz, ursprünglich habe die Tagung in Straßburg stattfinden sollen, sie sei jedoch von den französischen Behörden verboten worden. Daraufhin habe man den Sohlberg als Veranstaltungsort gewählt. Abetz an Obergebietsführer John (RJF-Personalamt), 1. 9. 1937; desgleichen in einer persönlichen Aufzeichnung „zum Vorwurf, vor der Machtergreifung aktiver Gegner des Nationalsozialismus gewesen zu sein“; BDC/ Abetz. Die Richtigkeit dieser Angaben steht dahin.

107 Steinthal, Jugendtreffen, S. 760; vgl. Abetz, Das offene Problem, S. 27; Unteutsch, Sohlbergkreis, S. 53. Abetz gab 1945 zu Protokoll, er habe Ostern 1930 im Anschluß an die Gespräche mit Luchaire auch Sangnier auf seinem Anwesen in Bierville aufgesucht. "Curriculum vitae“, pag. 4; AN, F 7/15331.

108 Im Aktenbestand PA/AA, R 98888.

109 Göttling an Geheimrat Terdenge (AA), 10. 7. 1930, ebenda. 
als Referent zu, was das landesweite Echo auf die Tagung verstärkte und dem Bekanntheitsgrad des wenig später gebildeten „Sohlbergkreises“ gewiß förderlich war ${ }^{110}$.

Viele Teilnehmer des Sohlbergcamps kamen zum ersten Mal mit Angehörigen des Nachbarlandes zusammen und empfanden die Begegnung als überaus anregend. Auf die Franzosen, an Großstadtgetriebe und die politisch-literarischen Diskussionszirkel der Pariser Salons gewöhnt, machten die von den Gastgebern demonstrativ vorgelebten Formen jugendbewegter, naturverbundener Gemeinschaft tiefen Eindruck. „Was - im guten Sinn - an ,Romantik in uns lebt, unser Fahrten- und Lagerleben, unsere Lieder, die Freundschaft und Aufgeschlossenheit unseres Gruppenlebens", habe die Gäste am stärksten fasziniert, berichtete Das junge Volk111. Etliche von ihnen schwärmten im Anschluß an die Tagung aus, um Deutschland und die bündischen Gepflogenheiten näher kennenzulernen. Der weltgewandte Journalist Silbert, der auf dem Sohlberg von seiner jüngsten Afrikareise erzählt hatte, besichtigte Heidelberg, Rothenburg, Nürnberg und Mannheim, überzeugte sich vom praktischen Nutzen des Herbergwesens und zollte den erzieherischen Leistungen der Jugendbewegung höchstes Lob: Sie forme körperlich gesunde, geistig rege, uneigennützige junge Menschen, biete ihnen Halt und Orientierung, was in schwierigen Zeiten wie diesen eine immense Beruhigung - gerade für das Ausland - darstelle. „En ces temps difficiles où l'Allemagne souffre politiquement, économiquement, moralement [...], la Jugendbewegung constitue, dans sa simplicité égalitaire, un refuge pour une jeunesse dont le standard de vie est moins élevé que le nôtre; c'est un magnifique creuset social en même temps qu'une école de raisonnement et de tolérance." Selbst der Umstand, daß sich Hitler-Anhänger in größerer Zahl offen zu erkennen gaben, vermochte Silberts positiven Gesamteindruck nicht zu trüben; er konnte keinen unlösbaren Widerspruch erkennen zwischen ihrer dezidiert nationalen $\mathrm{Haltung}$ und ihren Sympathiebezeugungen für Frankreich. Warum also „s'imaginer qu'un nationaliste allemand est automatiquement un ennemi de la France? "112

Zur blauäugigen Beurteilung künftiger Verständigungschancen verleitete nicht zuletzt der abgeschiedene, malerisch gelegene Tagungsort, ein wahrhaft konfliktfreier Raum hoch über den Niederungen des Alltags, wo „die Natur selber Fäden von Volk zu Volk spinnt “, wie Chronist Steinthal lyrisch beschwingt schrieb ${ }^{113}$. Manchen überwältigte das Gefühl, von einem solchen Punkt aus wäre die Welt zu kurieren. Jahre später erklärte Friedrich Bran ${ }^{114}$ den Sohlberg zu einer Art Kult-

110 Der Jungnationale Dähnhardt war auch Geschäftsführer der im Januar 1930 aus der Taufe gehobenen Volkskonservativen Vereinigung und gehörte ihrem Führerring an.

111 Das junge Volk, September 1930, S. 144. Vgl. Abetz, „Denkschrift" vom 30.4. 1931, pag. 3; AdJb, A 168/1.

112 Silbert, La jeunesse allemande chez elle, in: Notre Temps, 24. 8. 1930, Sp. 411-413.

113 Steinthal, Jugendtreffen, S. 760.

114 Friedrich Alexander Bran (Jg. 1904), in Karlsruhe aufgewachsener Verlegersohn, studierte nach einer Buchhändlerlehre Geisteswissenschaften in Frankfurt und Heidelberg (unter anderem bei Alfred Weber, Arnold Bergstraesser und Ernst Robert Curtius), promovierte 1929 mit einer Arbeit über Herder, engagierte sich in der Deutschen Freischar und der Arbeitslager-Bewegung. Die Lektüre von Hesse und Spengler weckte sein Inter- 
stätte („colline inspirée“) der deutschen und französischen Jugend ${ }^{115}$. „Rien d'officiel, rien de préparé, rien de politique", resümierte Jean Luchaire, der seine Erwartungen übertroffen und seinen Glauben an eine engverwandte Lebenseinstellung der jungen Europäer bestätigt sah ${ }^{116}$. In supranationalem Wir-Gefühl schwelgend, schilderte er seinen Lesern die Höhepunkte einer stets kameradschaftlich geführten, nur selten von Vorurteilen belasteten Aussprache, in deren Verlauf die Diskutanten "unzählige" Übereinstimmungen und wechselseitige Verpflichtungen entdeckt hätten. Alle seien sich darüber klargeworden, daß ein verheißungsvolles gemeinsames Aufbauwerk möglich sei117. Eben hierzu hatte Luchaire schon in seinem Schlußwort auf dem Sohlberg aufgerufen. Eindringlich beschwor er die Versammelten, nun, da sie um ihre annähernde Gleichheit (,identité presque complète") wüßten, nicht länger tatenlos nebeneinander her zu leben, sondern ihre Energien zu bündeln, gegen die verbohrten alten Männer an den Schalthebeln der Macht anzutreten und eine „neue Ordnung “ durchzusetzen. Gerechter Lohn der Mühen werde eine europäische Union auf der Grundlage eines deutsch-französischen Ausgleichs sein - „seul certitude de paix, seul certitude de prospérité“ ${ }^{118}$.

Daß die Sohlbergfahrer, ob sie es wahrhaben wollten oder nicht, letztlich Anwälte ihrer jeweiligen Landesinteressen blieben, enthüllten spätestens die handfesten Kontroversen, die in den folgenden Jahren untereinander ausgefochten wur-

esse an Völkerverständigung, ebenso die Verhandlungen zwischen Briand und Stresemann, die er 1928 in Genf als Journalist verfolgte. Nach dem Sohlbergtreffen 1930 nahm er Verbindung zu Abetz auf und war fortan maßgeblich an den Aktivitäten des Sohlbergkreises beteiligt. Im Frühjahr 1933 trat er in die NSDAP und die HJ ein; bis 1936 war er als Hauptreferent im Auslandsamt der Reichsjugendführung tätig. Er wurde Hauptschriftleiter der Deutsch-Französischen Monatshefte, offizielles Organ der Ende 1935 unter den Auspizien der Dienststelle Ribbentrop neugegründeten Deutsch-Französischen Gesellschaft, und blieb über den Kriegsbeginn 1939 hinaus ein sinnesverwandter Mitarbeiter und Weggefährte von Abetz. Brans Werdegang ist ausführlich nachgezeichnet bei Unteutsch, Sohlbergkreis, bes. S. 151 ff.; dies., Dr. Friedrich Bran - Mittler in Abetz' Schatten, in: Bock u. a. (Hrsg.), Entre Locarno et Vichy, I, S. 87-105.

115 Bran, Le pont de Saint-Jean de Losne?, in: DFM, Dezember 1934, S. 45. Bezeichnend die Formulierung im Reisebericht einer französischen Jugendgruppe vom Sommer 1934, auf den Sohlberg „gepilgert“ zu sein. In Zelten nächtigte man „à l'endroit même où eut lieu [...] la première rencontre des jeunesses franco-allemandes". Pierre Chérny, Jeunesse française en Allemagne, in: DFM, Oktober-November 1934, S. 39.

116 La Volonté, 8. 8. 1930.

117 Luchaire, Deux jeunesses en présence, in: Notre Temps, 10.8. 1930, Sp. 321-324. Die während des Camps geleistete Aufklärungsarbeit dünkte Luchaire bedeutsam, die Schubrichtung irreversibel: „Qu'on n'aille plus raconter aux jeunes Français du Sohlberg que les Allemands appartiennent à une race irréductiblement hostile à la France: ces jeunes Français hausseront les épaules. Qu'on ne prétende pas devant les jeunes Allemands du Sohlberg que les Français sont un peuple qui cherche à opprimer la race germanique: ces jeunes Allemands souriront avec dédain. Les uns et les autres sont devenus des amis." (Sp. 322) Von dieser Ausgabe an führte Notre Temps den Untertitel Revue des nouvelles générations européennes.

118 Luchaire, Discours final, ebenda, Sp. 355-358. Von seiner Kritik an den vergreisten Regierungsriegen, die keiner wegweisenden Impulse mehr fähig seien, nahm Luchaire seinen Mentor und Gönner Briand ausdrücklich aus. Vgl. ders., Les tendances politiques de la nouvelle génération française, ebenda, Sp. $347 \mathrm{f}$. 
den. Selbst bei Otto Abetz und seinen engsten Mitarbeitern scheint von Anbeginn eine gehörige Portion Nationalegoismus im Spiel gewesen zu sein, ein Verdacht, der erste Zweifel am sorgsam gepflegten idealistischen Habitus keimen läßt. Im Vorfeld der Tagung hatte Gustav Mittelstraß in Briefen an den Reichsminister für die besetzten Gebiete und das Auswärtige Amt hervorgehoben, es handele sich "nicht um eine von uns gesuchte Verbrüderung mit beliebigen Franzosen, sondern um den Versuch, national fühlenden Vertretern der beiden Völker die Möglichkeit einer Begegnung zu geben im Stile eines bündischen Jugendtreffens" ${ }^{\text {"119. }}$ Neun Monate nach dem Sohlbergtreffen verfaßte Abetz einen Bericht für den Staatspräsidenten und den Kultusminister von Baden, Reichsinnenministerium, Auswärtiges Amt sowie den Reichsausschuß deutscher Jugendverbände. Darin bekannte er sich zu den Prinzipien bündischer Grenzlandarbeit, zu denen er „Beeinflussung vor allem der jungen Ausländer zu Gunsten der deutschen Interessen" zählte, ein Ziel, das auf dem Sohlberg voll und ganz erreicht worden sei ${ }^{120}$. Für Dieter Tiemann, der erstmals auf dieses wichtige Dokument hingewiesen hat, offenbart sich hier „ein hoher Grad von Bereitschaft zur Konformität mit der offiziellen Politik, eine Angepaßtheit, über die drei Jahre später leicht verfügt werden konnte". Abetz habe frühzeitig einen "praktischen Sinn für die Vermarktung seiner Kreation" bei den Regierenden bewiesen und sich als Revisionist zu erkennen gegeben und zu profilieren versucht. Auf dem Sohlberg sei deshalb kein neues Kapitel bilateraler Beziehungen aufgeschlagen, sondern unter bemüht jugendspezifischem Gepräge „lediglich ein neuer deutscher Anlauf zu alten Zielen“ unternommen worden mit der Absicht, die öffentliche Meinung in Frankreich aufzuweichen ${ }^{121}$.

Anhaltspunkte, Abetz habe ein doppeltes Spiel getrieben - ein Makel, der seiner späteren Laufbahn unauslöschlich anhängt -, finden sich demnach schon in den Jahren 1930/31. Ob die Indizien genügen, ihm originären Idealismus gänzlich abzusprechen, erscheint indessen fraglich. Seine Überzeugung, daß der Versailler Vertrag ein Unding sei, war deutsches Allgemeingut, was ehrenwertes Bemühen um Revision nicht ausschloß. Die notwendige Flexibilität traute Abetz am ehesten der jungen Generation, seinesgleichen zu. Auf dem Sohlberg konnte die heikle Thematik ohne Gefahr für den Lagerfrieden angeschnitten werden, so von Heinz Dähnhardt, der ein Gutteil der wirtschaftlichen und politischen Schwierigkeiten des Reiches als Folgelast der „unglücklichen Lösung der Ostprobleme“ darstellte ${ }^{122}$. Daß der brennende Wunsch nach Wandel nicht zwangsläufig in gewaltbereiten Revanchismus auszuarten brauchte, wenn auch die Verhältnisse eine solche Entwicklung begünstigten, verdeutlichte Sohlbergreferent Otto Piper einige Monate später in einem Beitrag für Notre Temps. Deutschlands Jugend, so der Theologe, dürste nach sozialer Gerechtigkeit, nationaler Ehre und internationaler

119 Schreiben Mittelstraß' (Karlsruhe-Rüppurr) vom 5. 6. 1930; PA/AA, R 98887.

120 Abetz, „Denkschrift" vom 30. 4. 1931; AdJb, A 168/1.

121 Tiemann, Jugendbeziehungen, S. $116 \mathrm{ff}$. Nicht minder entschieden Rita Thalmann, Du Cercle de Sohlberg au Comité France-Allemagne, in: Bock u. a. (Hrsg.), Entre Locarno et Vichy, I, S. 67f., 85.

122 Zit. von Steinthal, Jugendtreffen, S. 763. 
Gleichberechtigung. Um der Integrität dieser Werte willen lehne man die niedere Gesinnung und Roheit der Nationalsozialisten ab, die freilich unverändert Zulauf hätten und vom jugendlichen Verlangen nach Visionen profitierten, solange das Ausland an der seither praktizierten Politik festhalte ${ }^{123}$. Die "Jeunes Turcs“ ihrerseits, klare Meinungsführer bei den französischen Sohlbergfahrern, hatten aus pazifistischem Antrieb, Europabegeisterung und im Zuge ihrer Systemkritik von jeher Verständnis für deutsche Gravamina gezeigt ${ }^{124}$. Während Luchaire nun dazu aufrief, sich speziell auch der nationalen Unterschiede bewußt zu werden und wohlwollend zu prüfen, ob sie einander beim großen europäischen Aufbauwerk nicht gewinnbringend ergänzen könnten ${ }^{125}$, stellte Guy Crouzet das friedensvertragliche Regelwerk gleich umfassend zur Disposition: „Si le Sohlberg avait duré quinze jours, quel assaut pour le traité de Versailles!" 126 Diese Männer mußten aus deutscher Sicht weder propagandistisch bearbeitet noch moralisch unter Druck gesetzt werden. Hatte Abetz sie schon damals vorsätzlich vereinnahmen wollen, dann waren sie allerdings ebenso leichte wie willige Beute.

Plausibel klingt die Erklärung, daß argwöhnische Ministerialbeamte alten Schlages, in deren Augen Kontaktaufnahmen über den Rhein vielfach noch etwas Landesverräterisches hatten, ohne deren Zustimmung und finanzielle Unterstützung jedoch wenig bewegt werden konnte, einstweilen durch Hervorheben "nationaler" Aspekte zu besänftigen waren. Mancher Behördenchef verweigerte sich trotzdem, im Falle des Sohlbergtreffens Reichsminister Treviranus, der es nachgerade als Zumutung empfand, eine Zusammenkunft mit Angehörigen einer „Besatzungsmacht" fördern zu sollen ${ }^{127}$. Das Auswärtige Amt sah sich unter Hinweis auf leere Kassen außerstande, einen Zuschuß zu bewilligen, und beschränkte sich auf die Erteilung geführenfreier Sichtvermerke ${ }^{128}$. Beihilfen gewährten schließlich das Reichsinnenministerium und das badische Kultusministerium ${ }^{129}$; quasi als Gegenleistung schickte Abetz einen schriftlichen Rapport, besagte „Denkschrift“. $\mathrm{Daß}$ er seine Argumentation auf die politischen Empfänglichkeiten der Sponsoren abstellte, liegt auf der Hand und fügt sich nahtlos in das Bild des gewieften Überzeugungskünstlers, das etliche Weggefährten von ihm zeichneten. Mit Vergnügen entsinnt sich Friedrich Bran seines Einfallsreichtums, um Unterstützung zu werben und Ziele auf Umwegen anzusteuern: „Da zeigten sich seine diplomatischen Qualitäten."130

Ebenso typisch für Abetz und die Annäherung an seine Person ist allerdings,

123 Otto Piper, La jeunesse allemande et Hitler, in: Notre Temps, 30. 11. 1930, Sp. $326 \mathrm{f}$.

124 Vgl. Berstein, Parti Radical, II, S. 104 f; Nordmann, Histoire des Radicaux, S. 238; Jouvenel, Voyageur, S. $77 \mathrm{ff}$. Nels schmähte den Versailler Vertrag als Werk gegenwartsfremder Revanchisten, die Reparationen als wirtschaftliche und den polnischen Korridor als politisch-geographische Absurdität; Fragments, S. 87.

125 Discours final, Sp. $357 \mathrm{f}$.

126 Crouzet, Huit jours franco-allemands, S. $199 \mathrm{f}$.

127 Der Reichsminister für die besetzten Gebiete an Gustav Mittelstraß (Abschr. ans Auswärtige Amt), 3. 7. 1930; PA/AA, R 98887.

128 Böhme (AA) an Mittelstraß, 17. 7. 1930, ebenda.

129 Abetz an Auswärtiges Amt, 3. 7. 1930, ebenda.

130 Befragung Bran, 18. 3. 1989. 
daß auf diesen an sich sympathischen Charakterzug sogleich ein Schatten fällt, gedenkt man der phantasievollen, teilweise hanebüchenen Rechtfertigungsversuche späterer Memoranden und Telegramme, deren Inhalt den selbstpostulierten Ansprüchen häufig diametral zu widersprechen scheint. Wer seine Korrespondenz aufrollt, stößt anderseits auf erstaunliche methodische Kontinuität im Dialog mit den Regierenden, ob es sich um Vorschläge für ,antijüdische Sofortmaßnahmen“ im besetzten Frankreich handelt ${ }^{131}$, mit denen angeblich noch Schlimmeres verhütet werden sollte, oder nur darum, störrischen Bürokraten Reiseerleichterungen abzuringen. Stets redet Abetz den Adressaten nach dem Munde, rückt ihre tatsächlichen oder vermuteten Interessen in den Mittelpunkt und präsentiert sich als nützlicher Helfer, wortreichen nachträglichen Beteuerungen zufolge immer im Bestreben, sich auf diese Weise persönlichen Handlungsspielraum zu erschließen. Dieses Verhaltensmuster, das bereits im Vorfeld des Sohlbergcamps aufblitzt, wurde ihm zur zweiten Natur. Sein Argument, daß zumal in einem totalitären System mit den Wölfen heulen muß, wer sie überlisten will, entbehrte nicht einer gewissen Logik. Der Graben zwischen den erklärten Motiven und den praktischen Auswirkungen seines Tuns aber weitete sich mit jedem Jahr, wesentlich bedingt durch die Schrankenlosigkeit des nationalsozialistischen Unrechtsregimes, mit dem er sich einließ. Abetz' Glaubwürdigkeit hat darunter gelitten, wurde nach Meinung vieler irreparabel lädiert. Tatsächlich stößt der Betrachter in wachsendem Maße auf Verstrickung und Schuld, hinter die die vorgeblich guten Absichten zuweilen bis zur Unkenntlichkeit zurücktreten. Abetz' Einlassungen zu dieser Thematik werden uns in den folgenden Kapiteln immer wieder beschäftigen. Während manche, auf zusätzliche Quellen gestützt, zu überzeugen vermögen, zumindest bedenkenswert erscheinen, verstimmen andere durch schiere Apologetik. In ihrer Gesamtheit stellen sie den Biographen vor nicht geringe interpretatorische Probleme und bedürfen einer kritischen Würdigung im Einzelfall132. Gerade deshalb aber wäre es unangemessen, aus bloßer Kenntnis seiner späteren, unstrittigen Verfehlungen schon die ersten Auftritte auf der deutsch-französischen Bühne in Bausch und Bogen als unseriöses Blendwerk zu disqualifizieren. Dagegen sprechen in eine andere Richtung weisende prägende Einflüsse, die der Heranwachsende erfuhr, und die rundum positive Beurteilung seiner Persönlichkeit durch alle - selbst künftige Gegner -, die ihn zu Sohlbergzeiten kannten ${ }^{133}$. Vorsicht gebietet überdies die schlichte Tatsache, daß Menschen sich entwickeln, auch

131 Abetz an Auswärtiges Amt, 20. 8. 1940; CDJC, LXXI-35.

132 Die Behauptung, Diktion und Inhalt seiner Vorschläge und Berichte hätten häufig nicht die eigene Meinung gespiegelt, seinen wahren Intentionen aber gerade durch das vordergründige Eingehen auf Mentalität und Erwartungshaltung des Empfängers den Weg ebnen sollen, war Dreh- und Angelpunkt der Abetzschen Verteidigung nach 1945. Er selber und frühere Mitarbeiter verbreiteten sich ausführlich über Notwendigkeiten und Finessen der taktischen Wortwahl, wobei sie sich eine unerschütterlich frankophile Gesinnung, ja sogar riskante Doppelspiele zu französischen Gunsten attestierten. Vgl. insbesondere die auf Angaben von Abetz beruhenden Aufzeichnungen Rudolf Schleiers, „Taktische Berichterstattung als Tarnung oder Mittel zum Zweck“ und „Berichterstattung einer diplomatischen Mission an ihr Ministerium“; PA/AA, Nachl. Schleier/IV.1, Nr. 7 und IV.2, Nr. 9.

133 Siehe Kap. II. 
zum Schlechten. In ihrer ganzen Vielschichtigkeit lassen sich am Fall Abetz reale und vermeintliche Möglichkeiten, durch die eigene Persönlichkeit und äußere Faktoren gezogene Grenzen des einzelnen studieren, auf die deutsch-französischen Beziehungen von damals Einfluß zu nehmen.

Das geglückte Experiment im Schwarzwald ermunterte zu neuen Taten. Am 26. Oktober 1930 konstituierte sich unter Leitung von Abetz innerhalb der Arbeitsgemeinschaft Karlsruher Jugendbünde ein „Kreis der Freunde des Sohlbergcamps". Er machte sich im darauffolgenden Jahr selbständig, weil seine Mitarbeiter inzwischen übers ganze Reich verstreut waren und nicht mehr ausschließlich der Jugendbewegung entstammten. „Gruppen in Stuttgart, Heidelberg, Freiburg, Düsseldorf und Berlin sind in Gründung", meldete im September 1931 die erste Ausgabe des von Abetz redigierten Vereinsblattes Soblbergkreis ${ }^{134}$. Obwohl die Mitgliederzahl nie sehr hoch war - Friedrich Bran beziffert den harten Kern auf "wenige Dutzend“" die Zahl der Sympathisanten mit "unter hundert" -, steigerte eine rührige Öffentlichkeitsarbeit rasch den Bekanntheitsgrad. Zu den Karlsruher Aktivisten gehörten außer Bran, Bentmann, Mittelstraß, Strauss und v. Grolman Kunsthallenchef Dr. Kurt Martin, Kapellmeister Joseph Keilberth und der Jugendheimleiter Artur Meißgeier. Von der Zeitschrift Soblbergkreis erschienen bis Mai 1932 drei Nummern; sie wurden - wie von Oktober 1934 an die DeutschFranzösischen Monatshefte - im Karlsruher Verlag G. Braun gedruckt, dessen Mitinhaber Friedrich Brans Vater war ${ }^{135}$.

Der Sohlbergkreis wollte „Zwischenstelle für deutsche und französische Jugendbestrebungen" sein, in Zusammenarbeit mit "Frankreichkennern“ Material für die Auslandsarbeit der Bünde bereitstellen und einen sachlichen Informationsfluß zwischen beiden Ländern fördern. Es sollte für keine bestimmte politische Losung geworben, sondern „der Versuch gemeinsamer außenpolitischer Schulung aller Richtungen“ unternommen werden. „Auf diese Weise sollen alle, die kein besonderes Frankreichstudium treiben können, die erforderlichen Kenntnisse erhalten, und die studierenden Romanisten sollen mit den aktiven Kreisen der deutschen Jugend zusammengeführt werden [...] Die Nationen sollen ihr Wesen durch die jungen Generationen offenbaren." 136 Pädagogischer Impetus, Experi-

134 Sohlbergkreis I, S. 2.

135 Befragung Bran, 18. 3. 1989.

136 Sohlbergkreis II (Dezember 1931), S. 22f. Wie dieser Ansatz in der Praxis aussah, verdeutlicht das Winterprogramm 1931/32 des Sohlbergkreises, dessen Abdruck wegen des hohen dokumentarischen Werts sinnvoll erscheint: „Die ersten vier Abende werden die Möglichkeiten einer Zusammenarbeit Deutschlands mit den großen Mächtegruppen untersuchen (Literatur ist in Klammern angegeben): 10.XI.: O. Abetz: Zusammenarbeit mit Frankreich? (Curtius, Französ. Kultur. Massis, Verteidigung des Abendlandes) - 26. XI.: O. Wagner: Ostorientierung (TAT-Aufsätze. Wirsing, Zwischen-Europa als deutsches Schicksal) - 7. XII.: G. Mittelstraß: Angelsächsische Nationen (Dibelius, England. M. J. Bonn, Amerika) - 21. XIl.: F. Bran: Kulturelle Autarkie? (Deubel, Deutsche Kulturrevolution. Viénot, Deutsche Unsicherheiten). Die fünf Abende nach Neujahr werden Sondergebiete in ihrer verschiedenartigen Ausprägung in Deutschland und Frankreich behandeln: 11. I.: O. Stolzer: Religiöse Lage (Jean Rupp, Découverte de la Chrétienté) 25. I.: A. v. Grolman: Literatur (Bücherangaben folgen) - 8. II.: K. Martin: Bildende Kunst (mit Lichtbildern) - 22. II.: W. Strauss: Wirtschaft (Bergstraesser, Frankreichs Staat 
mentierfreude und die Überzeugung, daß gemeinsames kulturelles Erbe über Grenzen hinweg verbindet, waren augenfällige Merkmale bündischen Handelns. Zudem stand der von Abetz und seinen Freunden gewählte Ansatz Arnold Bergstraessers Konzeption von der "kulturellen Begegnung" nahe, wie sie der Heidelberger Kulturhistoriker und Politikwissenschaftler in einer 1930 veröffentlichten programmatischen Abhandlung über Sinn und Grenzen der Verständigung zwischen Nationen entwarf, die die deutsche auswärtige Kulturpolitik, im besonderen den Studentenaustausch auf Jahre hinaus beeinflußte ${ }^{137}$. Bergstraesser, Jahrgang 1896, ehemals führendes Mitglied im „Wandervogel e.V.“, Wegbereiter des Akademischen Austauschdienstes und Teilnehmer des ersten Sohlbergtreffens ${ }^{138}$, verwarf internationalistische und pazifistische Annäherungsbestrebungen ${ }^{139}$. Er ging von der grundsätzlichen Dominanz nationalstaatlicher Machtinteressen aus. Verständigungsinitiativen diplomatischer oder wirtschaftlicher Natur hielt er insofern für untauglich, als sie den Status quo eher festigten denn im deutschen Interesse revidierten ${ }^{140}$. Auf Frankreich bezogen bedeutete dies, daß Eintracht mit dem westlichen Nachbarn nur in Bereichen möglich sei, „die nicht die Grundlagen der machtpolitischen Konstellation antasten, welche der Versailler Vertrag geschaffen

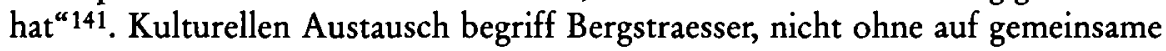
Wurzeln der europäischen Staaten zu verweisen, als „Kampf der geistigen Welten "142, als eine Konfrontation, die nicht in Aggression umzuschlagen brauchte, sondern durch persönliche Fühlungnahme Vorurteile zerstreuen, Verständnis wecken, ein positives Bild des eigenen Landes vermitteln und zugleich das nationale Selbstwertgefühl steigern konnte. Direkter Kontakt mit Ausländern erzwinge jene Aufmerksamkeit für den anderen, deren Fehlen erst „die fürchterlichen Ausmaße und die grotesken Formen des Hasses zwischen Nationen" er-

und Wirtschaft) - 7. III.: A. Meißgeier: Parteiwesen (Clauss, Frankreich. Siegfried, Das heutige Frankreich). Über ,Französ. Philosophie der Gegenwart' unterrichtet das Bändchen von Müller aus dem Verlag G. Braun (Karlsruhe) [...] Neben diesen Abenden findet noch eine Einführung in moderne französische Musik sowie eine Vortragsfolge von französ. Rednern (Revision, Regionalismus, Unterrichtswesen) statt, deren Daten noch bekanntgegeben werden. Zur laufenden Information des Kreises werden folgende Gebiete bearbeitet: Abrüstung: Meißgeier - Kriegsschuld: Minners - Minderheiten: Längin - Kolonien: Gäpfrich - Sozialpolitik: Seitz. - Jeder Mitarbeiter wird aus den ihm zugänglichen Zeitschriften und Zeitungen die für unsere Arbeit wichtigsten Artikel für das SohlbergArchiv (Belfortstr. 1 [= Abetz' Privatadresse]) ausziehen bezw. ausschneiden. " - Privatbesitz Bran (Kopie beim Verf.).

137 Vgl. Laitenberger, Theorie und Praxis der „Kulturellen Begegnung zwischen den Nationen“, S. $196 \mathrm{ff}$.; ders., Akademischer Austausch und auswärtige Kulturpolitik, S. 73 ff.; Meyer-Kalkus, Akademische Mobilität, S. 53 ff.

138 Biographische Angaben bei Kindt (Hrsg.), Dokumentation der Jugendbewegung, Bd. II, S. 1049; Meyer-Kalkus, ebenda, S. $54 \mathrm{ff}$.

139 Vgl. Bergstraesser, Sinn und Grenzen, S. $8 \mathrm{ff}$.

140 "Hinsichtlich [...] z.B. der Abrüstungsfrage, der Frage der Ostgrenze und des Anschlusses sich zu verständigen, hieße heute den Willen der Gegner zu dem seinigen machen, d.h. praktisch das Vorrecht selbstbestimmender staatlicher Gestaltung aufgeben." Ebenda, S. 89.

141 Ebenda, S. 17.

142 Ebenda, S. 73, 75. 
möglicht habe; natürliche Gegensätze würden „aus der immer blinden und ungesichtigen Sphäre der Ideologie in das Menschliche selbst" erhoben - gleichsam personifiziert -, was stereotypen Freund-Feind-Schemata vorbeuge ${ }^{143}$. Seien sich zwei Parteien über ihre jeweiligen Bedingtheiten im klaren, so könne aus dieser Erkenntnis "eine wirkliche Würdigung des anderen, eine gegenseitige Achtung“ erwachsen, die "trotzdem kein Aufgeben von Eigenem" bedeute und vielleicht einmal politische Früchte tragen werde. Einander verstehen heiße „ebensosehr sich gegen den anderen absetzen, wie ihn in sich aufnehmen". Solch komplementäres Zusammenspiel erachtete Bergstraesser für praktikabel, sofern die Beteiligten sich in fremde Gewohnheiten hineinzufühlen vermochten und über die „historische Sonderart der nationalen Gestaltungen" Bescheid wußten, anderseits fest genug in ihrer eigenen Kultur verwurzelt waren, um sie glaubwürdig und auf hohem Niveau zu repräsentieren - alles in allem Fähigkeiten, die nur von wenigen erwartet werden durften. Verständigung in diesem Sinn war mithin „Angelegenheit einer geistigen Oberschicht" 144 .

Nationalbewußtes Anforderungsprofil und elitäre Selbsteinschätzung, Methodik und Zielvorgaben entsprachen in hohem Maße den sowohl bei der jugendbewegten als auch der jungkonservativen Intelligenz verbreiteten Orientierungen. Die Möglichkeit langfristiger, werbender Einflußnahme auf die Meinungsbildung im Ausland, die Bergstraessers Theorie aufzeigt, hat die Arbeit des Sohlbergkreises ohne Zweifel inspiriert, der potentielle politische Nutzen kultureller Begegnungsaktivitäten den revisionistischen Ambitionen führender Mitglieder ein Betätigungsfeld eröffnet. Eine antithetische Sichtweise der Nationalcharaktere, als Mittel der Selbstfindung und angebliche Voraussetzung harmonischer auswärtiger Beziehungen, prägt die ab Herbst 1934 publizierten, von Abetz und Bran redigierten Deutsch-Französischen Monatshefte ${ }^{145}$. Über Bergstraesser hinaus wies Abetz' Bestreben, die "psychologische Annäherung der breiten Volksmassen“ voranzutreiben ${ }^{146}$, was dank der korporativen Teilhabe französischer wie deutscher Massenorganisationen an den zwischenstaatlichen Gesellschaftskontakten nach 1933 vordergründig zu gelingen schien, im Kalkül der nationalsozialistischen Machthaber jedoch vor allem ihren Expansionsdrang kaschieren sollte ${ }^{147}$.

Jugendbewegtes Gedankengut findet sich in einem Brief, den Friedrich Bran im November 1932, die jüngste Sohlbergkreis-Ausgabe kommentierend, an die Deutsche Botschaft Paris richtete: „Wir beginnen unsere Arbeit grundsätzlich von unten, das heißt beim einzelnen Menschen, aber wir glauben gerade dadurch allmählich für die Allgemeinheit etwas Nützliches leisten zu können." Dabei wolle man „so illusionsfrei wie möglich" vorgehen; Ziel sei eine sachlich-nüchterne Schulung für die außenpolitische Wirklichkeit, wofür jährliche Zusammenkünfte, Wanderungen, Skilager und ähnliche Veranstaltungen mit jungen Franzosen eine „sehr lebendige Grundlage“ böten. „Es würde uns freuen“, versicherte Bran dem

\footnotetext{
143 Ebenda, S. $65 \mathrm{ff}$.

144 Ebenda, S. 77 f. Bergstraesser dachte hierbei in erster Linie an Akademiker.

$145 \mathrm{Vgl}$. die Beispiele in Kap. IV.1 sowie Arend, Gleichzeitigkeit des Unvereinbaren, S. $145 \mathrm{ff}$.

146 Abetz, Das offene Problem, S. 61.

147 Arend, Gleichzeitigkeit des Unvereinbaren, S. 148.
} 
soeben in sein Amt eingeführten Botschafter Köster, „wenn wir dadurch auch Ihrer großen diplomatischen Mission nützlich sein könnten. "148 Köster erwiderte, die Botschaft verfolge die Aktivitäten des Sohlbergkreises schon seit geraumer Zeit und begrüße sie „aufs wärmste“, weil sie auf dem richtigen Ansatz fußten, „daß alle politische und diplomatische Arbeit letzten Sinnes vom einzelnen Menschen ausgehen und sich an den einzelnen Menschen richten muß". Ein reger Meinungsaustausch könne „auf die Dauer unseren beiden Völkern nur dienen und dazu beitragen, den Begriff Verständigung, mit dem so viele nicht zu Ende gedachte Ideen verbunden werden, durch die gegenseitige Achtung vor den nicht immer gleich laufenden Bedürfnissen und Zielen Deutschlands und Frankreichs zu ersetzen "149. Der Übereinstimmung signalisierende Schriftwechsel findet sich in einer seit Juni 1931 von der Pariser Vertretung geführten Akte "Soolbergkreis“ [sic!], die darauf hindeutet, daß die Karlsruher Initiative in deutschen diplomatischen Kreisen ein fester Begriff geworden und einigermaßen wohlgelitten war.

Auch die französischen Sohlbergfahrer trachteten nach einer soliden organisatorischen Verankerung ihrer Verständigungsarbeit. Unter Federführung der Notre Temps-Gruppe hoben sie im Juni 1931 das „Comité d'Entente des jeunesses françaises pour le rapprochement franco-allemand" aus der Taufe, dem binnen Monatsfrist sechs Jugend- und Studentenverbände mit zusammen rund 270000 Mitgliedern korporativ beitraten ${ }^{150}$. Stolz verkündete Notre Temps die Geburt des „mächtigsten Jugendkartells“, das Frankreich je gesehen ${ }^{151}$. In einem Gründungsaufruf, der unverkennbar die Handschrift des zum Vorsitzenden bestimmten Jean Luchaire trägt, erklärte das Comité, es wolle nationalistische Auswüchse bekämpfen und auf eine friedvolle Zukunft hinwirken, wofür die Verträge von 1919 keine ausreichende Sicherung darstellteri. Angestrebt wurde eine möglichst enge politische, wirtschaftliche und geistige Kooperation zwischen freiwillig assoziierten Völkern mit gleichen Rechten und Pflichten, ein geeintes Europa, das der unverzichtbaren Stütze einer deutsch-französischen Allianz bedürfe. Zu diesem Zweck wollte man jede Initiative fördern, die geeignet schien, vor allem junge Menschen beider Länder in freundschaftlichen Kontakt zu bringen, unabhängig vom weltanschaulichen oder konfessionellen Hintergrund ${ }^{152}$. Daß die deutsche Seite hierbei auf weitreichendes Entgegenkommen zählen durfte, ist den Erinnerungen WeilCuriels zu entnehmen, der als Generalsekretär des Comités fungierte und seine damalige Haltung so beschrieb: „avec toute mon ardeur, j'essayai de faire com-

148 Bran an Köster (Paris), 25. 11. 1932; PA/AA, Botschaft Paris 1050/1.

149 Köster an Bran, 19. 12. 1932, ebenda.

150 Association catholique de la jeunesse française, Jeunesses laïques et républicaines, Fédération des associations chrétiennes d'étudiants, Groupement universitaire franco-allemand, Foyer international des étudiants de Paris, Etudiants jeunes-républicains.

$151 \mathrm{La}$ jeunesse française pour le rapprochement franco-allemand, in: Notre Temps, 5. 7. 1931, Sp. 361 f. Siehe ferner DFR 4 (1931), S. 680 ff.; Revue d'Allemagne, 15. 8. 1931, S. $752 \mathrm{ff}$.

152 Vgl. Art. 2 und 3 der Vereinsstatuten, abgedruckt in Notre Temps, a.a.O. Das Comité konnte sich wohl nicht zuletzt deshalb so demonstrativ über parteipolitisches Gezänk erheben, weil extreme Gruppen wie Action Française und kommunistische Jugend in seinen Reihen fehlten. Auch im Sohlbergkreis spielten Extremisten - zumindest vorläufig keine ausschlaggebende Rolle. 
prendre aux Français les difficultés dans lesquelles se débattaient les Allemands, qui provoquaient chez eux des réactions qui nous heurtaient, mais qui n'étaient pas sans fondement. ${ }^{\text {} 153}$ Aufmerksam registrierte die Deutsche Botschaft Paris, daß es Luchaire, der in Kreisen der linksstehenden französischen Jugend eine führende Stellung erworben habe, dem doktrinären Laizismus der radikalsozialistischen Partei jedoch wie viele seiner Altersgenossen im Grunde fremd gegenüberstehe, gelang, eine Brücke zu wichtigen Organisationen der katholischen Jugend zu schlagen. Seine Persönlichkeit, urteilte Gesandtschaftsrat Kühn, sei „eine Bürgschaft dafür, daß es bei der bloßen Gründung des französischen Jugendausschusses [...] nicht sein Bewenden haben wird, und daß der ernsthafte Versuch gemacht werden wird, praktische und fruchtbare Arbeit zu leisten "154.

Eine Kostprobe seines kreativen Elans hatte Luchaire schon zu Jahresbeginn gegeben. Am 18. Januar 1931 veröffentlichte Notre Temps ein Manifest „contre les excès du nationalisme, pour l'Europe et pour l'entente franco-allemande", signiert von 186 Schriftstellern, Künstlern und Gelehrten. Sie verkörperten die Elite französischen Geisteslebens der Nachkriegszeit, wie die Initiatoren voller Stolz betonten. $\mathrm{Zu}$ den Unterzeichnern - bis April gesellten sich noch einmal 30 hinzu gehörten Marcel Arland, Julien Benda, Emmanuel Berl, Jean Cocteau, Pierre Drieu La Rochelle, Georges Duhamel, Alfred Fabre-Luce, Jean Galtier-Bossière, Jean Giono, Jean Guéhenno, Arthur Honegger, François Mauriac, André Maurois, Jean de Pange, Jean Paulhan, Jean Prévost, Jules Romains, Georges Suarez und natürlich die gesamte Entourage von Notre Temps. In einer Stunde, da Europa die Wahl habe, sich zu organisieren oder in einer neuerlichen Katastrophe unterzugehen, wollten sie ein Zeichen für Frieden und Ausgleich setzen; sie verurteilten Kriegstreiberei, forderten internationale Gleichberechtigung für alle Staaten und beteuerten, "que le vrai visage de la France n'est pas de haine et de guerre, mais de justice et de paix"155. Die Erklärung erregte beträchtliches Aufsehen, wurde von etlichen Pariser Zeitungen gedruckt und teilweise scharf kritisiert. Während La Volonté einen eindrucksvollen Beweis vorliegen sah, wie sehr das „Frankreich von morgen“ jenem schmalspurigen Nationalismus, den gewisse Blätter unverändert hochhielten, entsage, beklagte L'Action Française eine verantwortungslose intellektuelle „Mißgeburt“. Der Figaro wähnte gar eine Volkes Meinung entzweiende antifranzösische Verschwörung am Werk ${ }^{156}$. Um so größer war Luchaires Befriedigung, als am 27. Februar ein von annähernd 200 deutschen geistigen Kapazitäten getragenes Antwort-Manifest publik wurde. Der vom Berliner Pen-Club redigierte Text versicherte die französische Seite der uneingeschränkten Loyalität der Unterzeichnenden, befürwortete wärmstens gemeinsame Schrittmacherdienste für ein deutsch-französisches Rapprochement und ein ,neues Europa', bat aber auch um Verständnis dafür, daß die Friedensfreunde im Reich

153 Weil-Curiel, Eclipse en France, S. 124.

154 Kühn an Auswärtiges Amt, 18. 7. 1931; PA/AA, Botschaft Paris 1050/1.

155 "Le manifeste de Notre Temps ${ }^{*}$, abgedruckt in der Ausgabe vom 18. 1. 1931, Sp. 81-84; Luchaire, Histoire d'une initiative, ebenda, Sp. 85 f.; ders., Pas de temps d'arrêt dans l'œuvre intellectuelle, in: Notre 'Temps, 5. 4. 1931, Sp. $529 \mathrm{f}$.

156 Zit. nach Notre Temps, 8. 2. 1931, Sp. $210 \mathrm{ff}$. 
einen schweren Stand hätten: Außer der allgemeinen politischen Erregung und den Parolen der Ewiggestrigen dämpften besonders die Deutschland auferlegten moralischen und materiellen Folgelasten des Krieges, die als ungerecht und untragbar empfunden würden, die Versöhnungsbereitschaft. Die Unterschriftenliste, die in den kommenden Wochen noch anschwoll, vereinte so illustre Namen wie Georg Bernhard, Rudolf G. Binding, Ernst Robert Curtius, Alfred Döblin, Lion Feuchtwanger, Otto Grautoff, Walther Mehring, Heinrich und Thomas Mann, Rudolf Olden, Adolf Reichwein, Carl Sternheim, Jakob Wassermann, Ernst Wiechert, Theodor Wolff, Carl Zuckmayer und Arnold Zweig. „D'un côté comme de l'autre la bonne foi n'est couverte d'aucun voile“, resümierte Luchaire. „C'est ce que nous souhaitions." 157

\section{Europäischer Geist und völkische Ideen: Deutsch-französisches Treffen in Rethel 1931}

Den Jahreswechsel 1930/31 feierten 40 Studenten des „Groupement universitaire franco-allemand" mit ihren Freunden vom Sohlbergkreis auf einer Skihütte im Schwarzwald, „sous l'impulsion d'Otto Abetz, imprésario de classe“158. Ein zweiter großer Kongreß kam dann vom 2. bis 9. August 1931 in Rethel zustande. Luchaire hatte das im Krieg stark in Mitleidenschaft gezogene Ardennenstädtchen bewußt als Tagungsort gewählt, um auf diese Weise bei seinen Gästen Verständnis für das enorme französische Sicherheitsbedürfnis zu wecken ${ }^{159}$. Bedenken, die Retheler Bevölkerung könnte feindselig reagieren, erwiesen sich als unbegründet. "Es wurde wieder Wahrheit“, so Abetz, „daß Menschen, die selbst schwerstes Leid erduldet haben, oft am wenigsten dazu neigen, aus Rachsucht anderen wieder dasselbe zuzufügen, sondern vielmehr eine große Bereitschaft zeigen, das Ihre beizutragen, damit des Leids unter den Menschen wenigstens in der Zukunft etwas weniger werde." 160

Das Treffen fand in einer Landwirtschaftsschule statt und stand unter dem Motto „Französische und deutsche Jugend im Angesicht der europäischen Aufgabe“. Diese Aufgabe war seit dem Sohlbergcamp gewiß nicht leichter geworden. Die deutsch-französischen Beziehungen hatten sich im Gegenteil spürbar verschlechtert. Alarmiert verfolgten die Franzosen das Geschehen im krisengeschüttelten Nachbarland, wo Konkurse und Arbeitslosigkeit, gekürzte Sozialleistungen und höhere Steuern, politisches Chaos und zermürbende Not Hitler neue

157 „Manifeste de 188 intellectuels, artistes et savants d'Allemagne en réponse au manifeste de Notre Temps" und Stellungnahme Luchaires, in: Notre Temps, 8. 3. 1931, Sp. 369-373. Appelle vergleichbaren Zuschnitts lancierten im Krisensommer 1931 das "Comité franco-allemand d'information et de documentation " (vgl. Revue d'Allemagne, 15.7. 1931, S. 577 ff.) und die Deutsch-Französische Gesellschaft (15. August, S. 752 f.).

158 Weil-Curiel, La rencontre du Feldberg, in: Notre Temps, 8. 2. 1931, Sp. 247f.; Sohlbergkreis I, S. 2.

159 So Abetz' Darstellung als Zeuge im Luchaire-Prozeß; Les procès de collaboration, S. 488.

160 Abetz, Das offene Problem, S. 30. 
Wähler in Scharen zutrieben. Anläßlich der Reichstagswahl am 14. September 1930 entlud sich eine „sechzigmillionenfache Mischung aus Besorgtheit, Unruhe, Müdigkeit, Ratlosigkeit, Widerwillen, Erbitterung und Hysterie"161. 107 Mandate, statt der bisherigen zwölf, kürten die NSDAP zur zweitstärksten Fraktion im Parlament; auch andere Flügelparteien legten kräftig zu. Im März 1931 entbrannte zwischen Paris und Berlin eine hitzige Kontroverse um den Plan einer deutsch-österreichischen Zollunion, der als Präludium für einen politischen Anschluß der Alpenrepublik beargwöhnt wurde und selbst gestandene Männer des Ausgleichs wie Briand erzürnte ${ }^{162}$. Damit nicht genug: Eine Erklärung der Regierung Brüning vom 5. Juni, daß die wirtschaftliche und finanzielle Lage des Reiches "gebieterisch zur Entlastung Deutschlands von untragbaren Reparationslasten“" zwinge ${ }^{163}$, läutete die letzte Runde im Kampf um die Beseitigung der Kriegsschulden ein. Gegen den Vorschlag des amerikanischen Präsidenten Hoover, der den Europäern am 20. Juni ein Feierjahr für alle zwischenstaatlichen politischen Zahlungen offerierte, sträubten sich die Franzosen mehrere Wochen lang ein Zeitverlust mit fatalen Rückwirkungen auf die deutsche Wirtschaft, die von massiven Kapitalabzügen des Auslands beinahe stranguliert wurde ${ }^{164}$. Seit längerem schließlich schwelte der Streit um die deutsche Forderung nach mehr Gleichberechtigung in der Rüstung 165 .

$\mathrm{Daß}$ der Retheler Kongreß ungeachtet solcher Spannungen zustande kam, unterstreicht den guten Willen der Teilnehmer. Gar mancher habe sich gefragt, „ob es denn überhaupt noch einen Sinn macht, irgend etwas von einer Aussprache mit Frankreich zu erwarten", vermerkt ein zeitgenössischer Bericht ${ }^{166}$. Die untereinander geknüpften Bande waren der äußeren Belastung jedoch gewachsen. Immerhin aber hielt Abetz es für angebracht, das Auswärtige Amt vorab um Instruktionen zu ersuchen, wie sich die Reichsregierung eine Neuordnung Europas vorstelle, damit man den Franzosen „nichts Falsches“ sage ${ }^{167}$. Diese Rückversicherung ist einmal auf die stürmische politische Großwetterlage zurückzuführen, in der jede Unbotmäßigkeit amtliche Sanktionen auslösen konnte. In seiner Begrüßungsansprache in Rethel berichtete Abetz von materiellen und psychologischen Hürden, die seine Kameraden und er vor der Abreise nach Frankreich zu nehmen hatten; so sei man nur mit Mühe um eine unlängst verfügte drastische Erhöhung der Visagebühren herumgekommen ${ }^{168}$. Zum zweiten erscheint die Anfrage be-

161 Der linksliberale Publizist Leopold Schwarzschild, zit. von Schulze, Weimar, S. 326.

162 Vgl. J. Curtius, Bemühung um Österreich; Hauser, Der Plan einer deutsch-österreichischen Zollunion; Rödder, Stresemanns Erbe, Kap. VII; Schulz, Von Brüning zu Hitler, S. $298 \mathrm{ff}$., der das gesamte Krisengeschehen detailliert und die verschiedenen Ereignisstränge in ihren wechselseitigen Abhängigkeiten darstellt.

163 Abgedruckt in Schulthess' 1931, S. $120 \mathrm{f}$.

164 Vgl. Helbich, Reparationen.

165 Hierzu Geyer, Aufrüstung oder Sicherheit.

166 Deutsch-französisches Jugendtreffen in Rethel (Ardennen), in: Hochschule und Ausland 9 (November 1931), S. 19.

167 Abetz an Auswärtiges Amt, 31.7.1931 - eine auffallend kurzfristige Anfrage - , zit. bei Hardenberg, Bündische Jugend, S. 102. Eine Antwort wurde nicht ermittelt.

168 Notre Temps, 16.-23. 8. 1931 (Rethel-Sonderheft), Sp. 605 f. Am 27. Juli, eine knappe Woche vor Tagungsbeginn, schrieb Walter Strauss an Nora Gunzert aus Düsseldorf, die 
zeichnend für den persönlichen Stil des Bittstellers wie für einen augenfälligen strukturellen Wandel. Der Sohlbergkreis war nicht mehr jener verschworene, außerhalb Karlsruhes so gut wie unbekannte Zirkel von 1930, sondern auf dem besten Weg, sich einem landesweiten Publikum als Forum für deutsch-französische Begegnungen zu empfehlen. Mitgliederstarke Studentenverbände und Gruppen der Bündischen Jugend, etablierte zwischenstaatliche Organisationen und oberste Reichsbehörden nahmen inzwischen Notiz und Anteil an den Aktivitäten. Das setzte den Kreis verstärkt äußeren Einflüssen aus, zumal Abetz erklärtermaßen "die der jungen Generation gemeinsame Haltung [...] wahren" und zum Ausdruck bringen wollte ${ }^{169}$, ein Ziel, das ohne Berücksichtigung mächtiger weltanschaulicher Strömungen in Deutschland, an erster Stelle Revisionismus und völkisches Gedankengut, schwerlich zu realisieren war. Die Art, wie Abetz sich mit diesen politischen und geistigen Gegebenheiten arrangierte, ja identifizierte, verleiht seiner ursprünglich eher emotional begründeten Mittlerrolle schärfere, zunehmend von rechten Ideologien bestimmte Konturen.

Das rege Interesse an der Retheler Tagung mußte ihn freuen. Gleich zwei Dutzend zum Teil namhafte Organisationen aus dem Reich waren dort vertreten ${ }^{170}$. Nimmt man die französische Delegation hinzu, die ebenfalls viele tausend Landsleute repräsentierte, entsteht bei oberflächlicher Betrachtung leicht der Eindruck einer breitangelegten, rasch anschwellenden Verständigungsbewegung in beiden Ländern, die der erst vor Jahresfrist ergriffenen Karlsruher Initiative ein glänzendes Zwischenzeugnis ausstellt. Scheinbar folgerichtig wurde die Zusammensetzung der Retheler Runde denn auch als "Fortschritt“ gegenüber dem Sohlbergtreffen gepriesen, das noch überwiegend individuell interessierte Teilnehmer ohne Mandat vereint hatte ${ }^{171}$. Der primär informelle Charakter, der wie das nach jugendbewegter Manier zelebrierte Gemeinschaftserlebnis entscheidend zum harmonischen Verlauf des Schwarzwaldcamps beitrug, war freilich, wie sich bald herausstellte, dahin. Zwar schwärmen die vorliegenden Berichte von vielfältigen persönlichen und kulturellen Kontakten, doch wurden diese überlagert von inhaltlich scharfen Kontroversen in außenpolitischen Fragen, die fast ausnahmslos um

sich für Rethel angemeldet hatte: „Wir haben nun Mitteilungen aus Berlin und Frankfurt, ebenso in Karlsruhe, daß die Ausreisegebühr von RM. 100.- von Campteilnehmern nicht bezahlt werden braucht." Es folgten genaue Instruktionen, was zu tun wäre, sollten die Düsseldorfer Behörden bei der Visumausgabe Schwierigkeiten machen (Kopie des Briefes aus Privatbesitz Bran beim Verf.).

169 Sohlbergkreis I, S. 2.

170 Bund Deutscher Jugendvereine, Bund der Wandervögel und Kronacher, Mittelstelle deutscher Jugend in Europa, Neudeutschland, Sozialistische Jugend, Reichsausschuß Deutscher Jugendverbände, die Arbeitsgemeinschaften der Karlsruher, Stuttgarter und Württembergischen Jugendbünde, Christdeutscher Bund, Kinderfreunde, Leuchtenbergkreis, Reichsverband der Windthorstbünde, Turnerjugend, Wandervogel, Akademische Auslandsstelle, Deutsch-Französische Gesellschaft, Deutsch-Französisches Studienkomitee, Deutsche Studentenschaft, Deutscher Studentenverband, Deutsches Studentenwerk, Deutsche Studienstiftung, Frauenliga für Frieden und Freiheit, Politische Gesellschaften deutscher Hochschulen, Zentralverband der Angestellten. Teilnehmerliste in Notre 'Temps, 16.-23. 8. 1931, Sp. $603 \mathrm{f}$.

171 Deux jeunesses en présence, a.a.O., Sp. 601. 
deutsche Gravamina kreisten. Aller demonstrativen Verständigungsbereitschaft zum Trotz brachen latent vorhandene Gegensätze auf, sattsam bekannte Klischees erschwerten den Dialog. Weder waren die Deutschen gewillt, den Status quo in Europa länger zu ertragen, noch mochten die Franzosen leichthin Revisionen zugestehen. Insoweit spiegelte die Tagung nur das Gezänk in den nationalen Parlamenten, im Völkerbundsrat und anderenorts wider ${ }^{172}$.

Wie schon auf dem Sohlberg referierten Angehörige beider Nationen über Einzelfragen. Danach wurde im Plenum diskutiert. Die ersten Redner suchten noch eine euphorische Stimmung zu erzeugen oder hielten sich vornehm bedeckt wie André Berge, der den "tiefen Wunsch nach europäischem Geist“ in Frankreich betonte und meinte, das wahre Problem liege zunächst in der Anpassung von Denkweisen und Überzeugungen ${ }^{173}$. Rasch zeichnete sich indessen ab, was die deutschen Gäste sehr zum Verdruß ihrer Gastgeber umtrieb: Friedrich Bran zitierte Hans Freyers Satz „Frei ist der Mensch, wenn er in seinem Volk frei ist, und dieses in seinem Raum" 174 und appellierte an Frankreich, Europa dadurch zu dienen, „daß es die Not und die ewige Bestimmung des Deutschtums versteht". In den Forderungen nach Anschluß und Gleichberechtigung deutscher Minderheiten liege „die deutsche in der europäischen Aufgabe einbeschlossen“175. Gustav Mittelstraß konstatierte, daß im Reich eine beispiellose Enttäuschung über die Chancen internationaler Kooperation Platz greife, was eine allgemeine Steigerung des Nationalgefühls und eine Besinnung auf das Volkstum im In- und Ausland zur Folge habe ${ }^{176}$. Klartext redete auch der Geschäftsführer des Reichsausschusses deutscher Jugendverbände, Hermann Maaß. Er erläuterte den Zusammenhang zwischen Wirtschaftskrise und politischem Extremismus. Junge Menschen in Deutschland neigten in besorgniserregendem Ausmaß dazu, sich kollektiven Ideen zu unterstellen; die individualistische, vorwiegend kulturpolitisch orientierte Jugendbewegung sei am Ende. „Damit ist aber die Gefahr verbunden, daß man die geistige Bildung und Verantwortlichkeit des Einzelnen vergißt." Die fragwürdigen französischen Reparationsansprüche leisteten radikalen Tendenzen

172 Die Tagung von Rethel ist dokumentiert in: Notre Temps, 16.-23. 8. 1931, Une exploration psychologique franco-allemande; Sohlbergkreis I, S. 7-15; Benz, Deutsch-französisches Jugendtreffen in Frankreich, in: DFR 4 (1931), S. 782-785; Hochschule und Ausland 9 (November 1931), S. $19 \mathrm{f}$;; Berge, Après le congrès de Rethel, in: Notre Temps, 20./27. 9. 1931, Auszüge in deutscher Ubers. in Hochschule und Ausland 10 (Mai 1932), S. 22-27; G. M. (i.e. Gustav Mittelstraß), „Deutsch-französisches Jugendtreffen in Rethel, 2.-9. August 1931“ (masch. Aufzeichnung), AdJb, A 168/1; Weise, Deutsch-französisches Jugendtreffen in Rethel, S. 60-63, ein spätes, zur Verklärung neigendes Zeugnis eines Dabeigewesenen („Es waren Tage der Fülle; die Entdeckung von Freunden von jenseits der Grenzen ergriff uns wie ein Rausch [...] Wir waren bewegt, viele von uns wurden für das Leben gewandelt." ); siehe ferner Abetz, Das offene Problem, S. 30-32; Hardenberg, Bündische Jugend, S. 104-109; Tiemann, Jugendbeziehungen, S. 119-125; Unteutsch, Sohlbergkreis, S. 59-63.

173 Zit. nach Sohlbergkreis I, S. 14.

$174 \mathrm{Vgl}$. Freyer, Revolution von rechts, S. 69.

175 Sohlbergkreis I, S. 15.

176 Ebenda, S. 13. 
Vorschub; gerade Jugendliche empfänden die Zahlungen als pure Erpressung, nicht als Wiedergutmachung ${ }^{177}$.

Nicht nur in diesem Punkt stimmte der Sozialist Maaß178 mit dem rechtsstehenden Außenamtsleiter der Deutschen Studentenschaft, Walther Reusch, überein. Der nahm ebenfalls kein Blatt vor den Mund und prangerte die in seinen Augen skandalöse Tatsache an, daß die deutschen Gelder nicht zur Behebung von Kriegsschäden, sondern zur Tilgung alliierter Schulden bei den Vereinigten Staaten verwendet würden: „Das ist nicht mehr Reparation, sondern Tribut!“ Er verlangte Expansionsmöglichkeiten für die deutsche Wirtschaft in Südosteuropa und als "Grundbedingung für jede ernste Zusammenarbeit" den Widerruf der These von der deutschen Alleinschuld am Krieg. Den Volkstumsgedanken bemühend, hielt er es für angezeigt, deutsche Minderheiten entlang der Reichsgrenzen mit dem Mutterland zu vereinigen und Deutschstämmigen in weiter entfernten Gebieten kulturelle und korporative Autonomie zu gewähren. Ein sofortiger Anschluß Österreichs sei nicht nur in diesem Zusammenhang, sondern auch aus wirtschaftlichen Gründen zwingend geboten. Reusch und andere beteuerten, das seien "wahrhaft europäische Vorstellungen" ${ }^{179}$, ernteten jedoch energischen Widerspruch. „Fast geschlossen“, so der Korrespondent einer regionalen Tageszeitung, sträubte sich das Empfinden der französischen Zuhörer gegen die vorgebrachten völkischen Theorien, die sich politischer Ratio zu entziehen und von einer neuen Flutwelle des Nationalismus zu künden schienen ${ }^{180}$. Allen voran warnte Pierre Brossolette die Gäste davor, ihren „Dynamismus“ auf eine bloße Restauration der Vergangenheit und die Rückeroberung alter Grenzen zu richten. Speziell das Volkstumsprinzip tauge nicht als Fundament einer fruchtbaren Kooperation, es werde von den meisten Franzosen als bedrohliches Hegemonialstreben gedeutet. Frankreich und Deutschland sollten sich besser auf ein wahrhaft schöpferisches Programm verständigen und die europäische Union verwirklichen, samt Rüstungskonvention und Schiedsgericht. Mit einem solchen Instrumentarium wären übertriebene Härten des Versailler Vertrages dann leicht zu korrigieren $^{181}$.

Ein Kompromiß zwischen beiden Modellen wurde nicht gefunden. So blieb dem spürbar enttäuschten Jean Luchaire nur übrig, die Versammelten fast flehentlich zu bitten, die Suche nach einem gangbaren Mittelweg entschlossen fortzuset-

177 Ebenda, S. 9.

178 Hermann Maaß (Jg. 1897) entstammte der zur SPD gehörigen Sozialistischen Arbeiterjugend, die sich für die Weimarer Republik engagierte und führend am Reichsausschuß der deutschen Jugendverbände beteiligte. Nach 1933 stieß er zum Widerstand. Im Oktober 1944 wurde er in Plötzensee hingerichtet.

179 Sohlbergkreis I, S. $10 \mathrm{f}$.

180 Nord-Est, 8. 8. 1931. Nels’ Erinnerungen stützen diese Beobachtung: „Le congrès est décevant. Les Allemands, intarissables, ne répondent pas aux questions des Français et semblent déjà gagnés par un nationalisme exacerbé." Fragments, S. 118.

181 Sohlbergkreis I, S. $11 \mathrm{f}$. Luchaire hatte schon auf dem Sohlberg eine „Entwertung der Grenzen " (dévalorisation des frontières“) gefordert. Er dachte an eine Bereinigung von Grenz- und Territorialfragen im Rahmen einer europäischen Föderation, die allein imstande wäre, die geistige und politische Freiheit nationaler Minderheiten zu sichern. Vgl. Notre Temps, 10.8. 1930, Sp. 356. 
zen. Hierbei müßten beide Seiten zu Abstrichen an ihren Idealvorstellungen bereit sein; niemand dürfe sich darauf versteifen, Europa exklusiv nach eigenem Gusto gestalten zu wollen. Die Deutschen stünden in der Pflicht, ihre fatale germanische Egozentrik zu überwinden, betonte er mit mühsam gezügeltem Unmut; gefragt sei ein höherer, kontinentaler Patriotismus. Seinen Landsleuten empfahl er, Deutschlands unmittelbaren Bedürfnissen in schwerer Zeit vermehrt Beachtung zu schenken und dem Eindruck entgegenzuwirken, Frankreich sinne nur auf eine wohlfeil verpackte Kopie der ungerechten, hastig improvisierten Regelungen von 1919. Um einen versöhnlichen Ausklang bemüht, konzedierte er den rechtsrheinischen Nachbarn, Niederlage, Besetzung und Inflation hätten sie verständlicherweise gegen demokratische und ökonomische Gepflogenheiten des Westens eingenommen. Getrieben von derselben inneren Unruhe und gleichermaßen unzufrieden mit den herrschenden Verhältnissen, müsse die junge Generation beider Länder jedoch über alle zeitweiligen Meinungsverschiedenheiten hinweg Solidarität üben ${ }^{182}$. Auch Abetz beschwor die Anwesenden, an einem Strang zu ziehen. Er verknüpfte seinen Appell mit düsteren Prophezeiungen, die Besorgnis ob der ungewissen Entwicklung wie auch anderseits eine unterschwellige Tendenz erkennen lassen, die französischen Gesprächspartner moralisch unter Druck zu setzen. Gelinge es nicht, die Regierenden in Paris und Berlin auf Verständigungskurs zu zwingen, drohe eine gefährliche Zuspitzung der Lage. Gewännen Nationalisten oder Kommunisten die Oberhand im Reich, würden sie das Geschehen auf unabsehbare Zeit bestimmen. „Nous sommes prêts à créer un homme nouveau: le jeune Européen", behauptete Abetz, schränkte aber sogleich ein, für die krisengeschüttelten Deutschen bedeute europäische Zusammenarbeit zunächst eine wirtschaftliche Notwendigkeit, wohingegen sie sich außerstande sähen, die weitgreifenden politischen Visionen der französischen Freunde im gewünschten Tempo zu konkretisieren ${ }^{183}$.

Die Euphorie war gewichen, der Traum von einer jugendlichen Internationalen, die unwiderstehlich das Tor in eine bessere, gemeinsame Zukunft aufstößt, erst einmal zerplatzt. Vor dem Hintergrund wachsender internationaler Spannungen traten nationale Befangenheiten auch in diesem vorgeblich progressiven Kreis akzentuiert in Erscheinung, besonders auf deutscher Seite ${ }^{184}$. Die gelöste Aufbruchstimmung des Sohlbergcamps blieb Episode - die in Rethel versammelten Franzosen, unter ihnen kritische Analytiker wie Robert Aron und Philippe Lamour, ferner Pierre Viénot, der gerade ein Buch über die „incertitudes allemandes“ veröf-

182 Luchaire, „Discours final“ (9. 8. 1931), in: Notre Temps, 16.-23. 8. 1931, Sp. 654-662.

183 „Discours final d'Otto Abetz“, ebenda, Sp. 651-654.

184 Etlichen, auch neutralen Beobachtern erschien diese Form bilateraler Kommunikation dennoch unvermindert richtungweisend. Der päpstliche Osservatore widmete dem Retheler Treffen einen ausführlichen Bericht und kommentierte, die Gespräche hätten das gegenseitige Verständnis bestmöglich gefördert und die einer Annäherung entgegenstehenden Hindernisse aufgezeigt. Nach Einschätzung des französischen Geschäftsträgers beim Heiligen Stuhl, Gentil, stellte die Veröffentlichung nicht zuletzt eine Ermahnung an die faschistischen Machthaber in Rom dar, die Italiens Jugend mitnichten zur Völkerverständigung erzögen. Gentil an Briand, 18. 8. 1931; MAE, Europe 1918-1940, Allemagne 739. 
fentlicht hatte ${ }^{185}$, schwankten zwischen Erstaunen und Entsetzen über den dezidiert revisionistischen, der regierungsamtlichen Linie verhafteten Standpunkt der Gäste, den sie in solch geballter Konsequenz nicht akzeptieren mochten ${ }^{186}$. Die deutschen Konferenzteilnehmer ihrerseits monierten mangelnde Sensibilität für den Volkstumsgedanken. Erich Benz, künftiger Leiter des deutsch-französischen Schüleraustauschdienstes, verstieg sich in die dümmliche Folgerung, der Franzose besitze eben "kein nennenswertes Rasseempfinden, wie er ja auch dem Eindringen fremden, farbigen Blutes, im Süden des Landes beispielsweise, kaum einen Widerstand entgegensetzt ${ }^{\text {"187. }}$. Hier artikulierte sich ein Überlegenheitsdünkel, der menschenverachtende Trennlinien zog.

Otto Abetz hatte sich von den lauter gewordenen Revisionsforderungen nicht distanziert. Er teilte sie im Grundsatz und versuchte, sie mit der deutschen Not zu erklären. Bemüht, den Dialog aufrechtzuerhalten und einen friedlichen Wandel zu fördern, lag ihm daran, französische Befürchtungen zu zerstreuen, der in Rethel massiv herausgekehrte Volkstumsgedanke künde von einer neuen nationalistischen Bedrohung. Erste Gelegenheit zur Beschwichtigung bot Ende August eine dreitägige Zusammenkunft von Mitgliedern des Sohlbergkreises mit vierzehn französischen Studenten und Dozenten, die als Vertreter des Weltstudentenwerks Deutschland bereisten. Abetz nutzte die Aussprache auf dem Kniebis im Schwarzwald, um das Verhältnis der Jugendbewegung zum Volkstumsbegriff und die damit verbundenen inhaltlichen Vorstellungen zu erläutern. Sein Vortrag, zwei Wochen später in französischer Übersetzung von Notre Temps abgedruckt und auf diese Weise einem größeren Publikum zugänglich gemacht, war der idealisierenden Leitidee einer organisch gegliederten "Volksgemeinschaft" verpflichtet, die in den Bünden beispielhaft vorgelebt werden sollte, auf einer im Wortsinne erwanderten Liebe zu Heimat und Brauchtum fußte und sich durch ihren im Kern apolitischen Ansatz grundlegend von den aggressiven Blut- und Bodentheorien völkischer Agitatoren unterschied ${ }^{188}$. Autonomiestreben und erzieherische Impulse der Wandervogelzeit, so Abetz, besäßen für die Bündischen nach wie vor Gültigkeit. Mehr noch: dieser Geist, wichtiges Charakteristikum der neuen Hinwendung zum Volkstum und zugleich potentieller Schrittmacher einer deutschfranzösischen Annäherung, habe sich ausgebreitet und selbst junge Nationalsozialisten vereinnahmt ${ }^{189}$. Die letzte Behauptung, die im Rückblick wie ein frühes Beispiel irreführender Verharmlosung des Nationalsozialismus aus seinem Munde

185 Viénot, Incertitudes allemandes. Das Buch wurde umgehend ins Deutsche und Englische übersetzt.

186 Während einer Diskussion brauste Luchaire auf, die Deutschen hielten an imperialistischem Gehabe fest, während sich seine Landsleute größte Mühe um eine verantwortungsbewußte Gestaltung der künftigen Beziehungen gäben; Notre Temps, 16.-23. 8. 1931, Sp. 650. Mittelstraß nannte drei Faktoren für das Auftreten der deutschen Delegation: „Unsicherheit des Lebensgrundes, grenzenlose Enttäuschung in allen Fragen, die den Völkerbund betreffen, und das Erlebnis des Volkstums“; "Deutsch-französisches Jugendtreffen", pag. 2.

187 Benz, Deutsch-französisches Jugendtreffen, S. 783.

188 Vgl. Raabe, Bündische Jugend, S. $115 \mathrm{ff}$.

189 Abetz, Mouvement de jeunesse et „Volkstum“, in: Notre Temps, 13. 9. 1931, Sp. 78-80. 
anmutet, bezog ihren Optimismus möglicherweise aus der Tatsache, daß sich die $\mathrm{HJ}$ respektive der NS-Schülerbund auf sein Betreiben hin seit 1927 an Aktivitäten und Veranstaltungen der Arbeitsgemeinschaft Karlsruher Jugendbünde beteilig$\operatorname{ten}^{190}$.

Das nächste Heft des Soblbergkreises faßte die Diskussion im Anschluß an Abetz' Referat zusammen. Trotz seiner zuversichtlichen Aussagen sparten die französischen Gäste nicht mit kritischen Fragen. Unvermindert besorgt, am „Volkstum“ könnte sich ein gefährlicher Nationalismus entzünden, regten sie an, doch besser nach französischem Vorbild in „europäischen“ Kategorien zu denken. Die Antworten der Gastgeber dokumentieren einmal mehr, wie sehr Vergangenheit und krisenhafte Entwicklungen auch auf jungen Leuten lasteten, die erklärtermaßen anders als ihre Väter miteinander umgehen wollten, und sie in ihrer Argumentation festlegten. Volkstümliches Empfinden sei "natürlich und gut", insistierte ein von dem Chronisten als „linksradikal“ eingeschätzter Teilnehmer; „es entartet erst, wenn der Kapitalismus den Bazillus Nationalismus in die natürliche Liebe des Volkes zu seiner Heimat und Eigenart hineinpflanzt und sie für seine Zwecke und Kriege mißbraucht". An anderer Stelle wurde zwar eine Tendenz zu Übertreibungen eingeräumt, zugleich aber unmißverständlich betont, daß Deutschlands Jugend sich und ihr Volk den saturierten Nachbarn gegenüber in der Rolle des „Proletariers“ sehe, dem nur ein leidenschaftliches „Klassen-“, sprich Nationalbewußtsein dazu verhelfen könne, "den notwendigen wirtschaftlichen Lebensraum und die politische Gleichberechtigung zu erlangen". Dieses Bewußtsein werde sich solange steigern wie die deutsche Not. Nicht zuletzt die Parabel vom europäischen Klassenkampf entlarvte den beflissen idealisierten Volkstumsgedanken als ideologische Stütze des Revisionismus ${ }^{191}$.

Drei weitere Beiträge im Dezemberheft des Soblbergkreises versuchten ein brisantes Thema aufzuarbeiten, vermochten indes die spezifisch ausgeprägte deutsche Staatsauffassung des „Volkes“, basierend auf identischer Herkunft und Sprache, „Wesensverwandtschaft" und „Eigenart", und die französische von der „Nation", gegründet auf einheitliche Lebensform, Bildung und politische Geschichte, ebensowenig in Einklang zu bringen wie die Diskussionszirkel in Rethel und auf dem Kniebis ${ }^{192}$. Das Zeitgeschehen war eher geeignet, Vorbehalte und Vorurteile zu schüren, anstatt sie abzubauen. Konnte ein ,guter Deutscher' auf den Anspruch der Gleichberechtigung, ein ,guter Franzose‘ auf die Erfüllung seiner Sicherheits-

190 So Abetz’ Darstellung von 1937 „zum Vorwurf, vor der Machtergreifung aktiver Gegner des Nationalsozialismus gewesen zu sein“; BDC/Abetz, von Abetz für ein SS-Verfahren zusammengestelltes Entlastungsmaterial, Aufzeichnung IIIa.

191 Vom Kniebistreffen, in: Sohlbergkreis II, S. 11-13.

192 Friedrich Bran versicherte unverdrossen, deutsches Volkstum in Europa kennzeichne in erster Linie eine kulturelle und soziale Schicksalsgemeinschaft, politischer Anschluß aber werde nur dort gefordert, wo die Reichsgrenzen unmittelbar tangiert wären; ebenda, S. 5-8. Louis Dumat, junger Pariser Abgeordneter und Mitglied der rechtsgerichteten Jeunesses Patriotes, bestätigte, daß etliche deutsche Manifestationen in Frankreich als neue Anzeichen von Pan-Germanismus gewertet würden; S. $3 \mathrm{f}$;; François Berge wünschte sich eine "vom Bewußtsein der allgemein menschlichen Verbundenheit“ getragene Ergänzung von Heimatliebe und Zugehörigkeitsgefühl zu Europa; S. 8-11. 
bedürfnisse verzichten? Schlossen Glück und Größe des einen Vaterlandes Geltung und Selbstbehauptung des anderen ein für allemal aus? Gerade die junge Generation beider Länder, so Abetz, habe „wegen der ehrlichen Sympathien, die sich zwischen ihr bereits über die Grenzen gebildet hatten, das Unausweichliche, die Tragik und Gefährlichkeit dieser Fragestellung “ empfunden ${ }^{193}$.

\section{Rückzug in nationale Bastionen: Die Mainzer Tagung 1932}

Einen weiteren Dämpfer erlitten die Vermittlungsbemühungen sieben Monate später, beim dritten Kongreß des Sohlbergkreises vom 21. bis 26. März 1932 in Mainz. Rund 100 Teilnehmer stiegen in der Karwoche zur alten Zitadelle hinauf, bis 1930 Quartier für französische Besatzungstruppen, nun Sitz eines Instituts für Völkerpädagogik und Begegnungsstätte ${ }^{194}$. Die Leitung des Treffens oblag Friedrich Bran und Abetz, der am Schlußtag seinen 29. Geburtstag feierte, Anlaß für Cecil Mardrus, seine Verdienste um die deutsch-französische Verständigung in einer beschwingten Laudatio zu würdigen ${ }^{195}$. An der Spitze der französischen Delegation stand François Berge, seinerzeit Lektor an der Universität Heidelberg. Jean Luchaire mußte wegen einer schweren Erkältung auf die Teilnahme verzichten; sein mitreißender, Mißklänge zudeckender Enthusiasmus fehlte allenthalben. Erneut ging es um die politische, wirtschaftliche und kulturelle Lage in beiden Ländern, doch von Harmonie konnte kaum mehr die Rede sein. Das Bemühen einzelner um Sachlichkeit wurde immer wieder durch den Radikalismus anderer durchkreuzt. Das lag zum einen an der vermehrten Anwesenheit rechtsextremer Kräfte - Action Française, Jeunesses socialistes nationales (Hervé-Jugend) und erstmals auch Vertreter von HJ und NSDAP196 -, die mit den "Weltbürgerlichen“ zankten, ein Gegensatz, der sogar landsmannschaftliche Fronten sprengte: Einer Kranzniederlegung zu Ehren Stresemanns wohnten französischer- wie deutscherseits fast ausschließlich Angehörige linksgerichteter Verbände bei, während die

193 Abetz, Das offene Problem, S. 32.

194 Ursprünglich war Aachen als Tagungsort vorgesehen. Die Veranstalter des Sohlbergkreises sprachen von 120 , Walther Reusch nur von etwa 80 Gästen. Die Tagung ist ausführlich dokumentiert in Sohlbergkreis III-IV (Mai 1932), einem Doppelheft, das auf 32 Seiten Vorträge und Diskussionen zusammenfaßt, und in einer Spezialausgabe von Notre Temps, 3.-10. 4. 1932. Siehe ferner: Hartmann, Die Jugend baut Brücken, in: DFR 5 (1932), S. 367-369; Reusch, Drittes deutsch-französisches Treffen des Sohlbergkreises, in: Hochschule und Ausland 10 (Mai 1932), S. 14-20; Roßmann, Deutsch-französische Jugendaussprache. Die Arbeit des Sohlbergkreises, in: Kölnische Zeitung, 18. 4. 1932; Abetz, Das offene Problem, S. 32 ff.; Hardenberg, Bündische Jugend, S. 109 ff.; Tiemann, Jugendbeziehungen, S. $125 \mathrm{ff}$; Unteutsch, Sohlbergkreis, S. $65 \mathrm{ff}$.

195 Notre Temps, 3.-10. 4. 1932, Sp. 495.

196 Neu dabei waren auf deutscher Seite außerdem: Reichsverband deutscher Zentrumsstudenten, Hochschulgruppe der Deutschen Volkspartei, Deutsche Freischar, Quickborn, Neudeutschland, Katholische Weltjugendliga, Bund religiöser Sozialisten, Deutsche Turnerschaft, Deutsch-französischer Arbeitskreis für Wirtschaftspolitik; vgl. ebenda, Sp. 442. 
rechten Flügel beider Delegationen grenzübergreifend Kampfstellung gegen „Pazifisten" und „Internationalisten" bezogen ${ }^{197}$. Zugleich stand auch dieser Kongreß ganz im Zeichen der Weltwirtschaftskrise ${ }^{198}$, die immer katastrophalere Auswirkungen besonders in Deutschland zeitigte, was den Ruf nach Revisionen noch lauter erschallen und Meinungsverschiedenheiten noch schärfer hervortreten ließ. Unter solchen Bedingungen setzte sich der schon in Rethel deutlich gewordene "Rückzug in nationale Bastionen " 199 fort, eine Entwicklung, die namentlich den Deutschen geradezu als ein Gebot der Stunde erschien. „Die außenpolitische Haltung Deutschlands muß einheitlich sein", postulierte im Anschluß an die Tagung das von Abetz redigierte Vereinsorgan Soblbergkreis und signalisierte unmißverständlich, daß transnationale Begegnungen inzwischen auch von diesem Zirkel primär als Bühne für die Zurschaustellung und Abgrenzung deutscher Interessen begriffen wurden. Bereitschaft zur Auseinandersetzung mit Angehörigen eines anderen Landes, so hieß es, verlange „nicht nur ehrliche Gesinnung, sondern klare Erkenntnis der eigenen Artung und des Eigenrechts jeder Nation"200. Die Betonung verbindender Elemente verblaßte demgegenüber mehr und mehr und vermochte für den Augenblick keine wesentlichen Impulse mehr zu geben. Die getreuen Partner von Notre Temps, mit Briands Tod am 7. März ihres Mäzens und geistigen Mentors beraubt, hatten zwar unverdrossen an der Vision einer europäischen Union auf der Grundlage eines deutsch-französischen Ausgleichs festgehalten und sich auch durch massive Vorbehalte skeptischer Landsleute nicht davon abbringen lassen, den Dialog fortzusetzen, doch trauerten sie besseren Zeiten nach: „On ne chanta guère [...] Nous étions loin de Rethel ou du Sohlberg“", resümierte Leitartikler Claude Bordas mit nostalgisch verklärtem Blick zurück. Immerhin, so tröstete er sich und seine Leser, bestünden allen politisch-ideologischen Gegensätzen zum Trotz „liens profonds et intimes“; darüber hinaus habe sich die junge Generation in Mainz zumindest unverstellt und in ihrer ganzen Komplexität offenbart ${ }^{201}$.

Die französischen Tagungsgäste mußten sich den offenen Vorwurf gefallen lassen, ihre Regierung schüre durch einen „brutalen“ Wirtschaftskrieg Not und Anarchie im Nachbarland, "mit dem Ziel einer vollkommenen Lahmlegung von Wirtschaft und Handel"202. Eindringlichen Schilderungen des sozialen Elends und der gefahrvollen politischen Zuspitzung im Reich folgten, mehr oder weniger moderat formuliert, die bekannten Forderungen nach Streichung der Reparationen und nach wirtschaftlichen Einflußzonen in Südosteuropa. Hermann Maaß machte deutlich, daß Deutschlands Jugend ungeachtet der Frage der Zahlungsfähigkeit nicht länger gewillt sei, Verpflichtungen nachzukommen, „ür die sie in-

197 Vgl. Abetz, Das offene Problem, S. 33.

198 "Le Congrès fut dans l'incapacité absolue et compréhensible de se détacher du fait primordial de la crise“, so das um Wohlwollen bemühte Urteil eines französischen Beobachters; Léon-Marie Brest, Mayence, Pâques 1932, in: Notre Temps, 3.-10. 4. 1932, Sp. 445.

199 Tiemann, Jugendbeziehungen, S. 130.

200 Sohlbergkreis III-IV, S. 4.

201 Claude Bordas, Une seule jeunesse, in: Notre Temps, Sp. $439 \mathrm{ff}$.

202 Diskussionsbeitrag von Edmund Holdmann, nach eigenem Bekunden „extremer Nationalist“; Sohlbergkreis, S. 12. 
nerlich sich nicht verantwortlich fühlt" ${ }^{203}$. Cecil Mardrus, der unterstrich, daß „die Franzosen die Deutschen nicht mehr zwingen [können], bezahlen zu wollen", und die Vertreter der Jeunesses socialistes nationales zeigten in diesem Punkt Entgegenkommen; letzte vermeldeten sogar in territorialer Hinsicht und auf dem Rüstungssektor Kompromißbereitschaft ${ }^{204}$. Für Aufregung sorgte dagegen Walther Reuschs Ansinnen, im Zuge einer „konstruktiven Revision“" müsse Paris der bodenständigen deutschen Kultur im Elsaß „ungehinderte Entwicklungsmöglichkeit" garantieren. Allemal befremdlich für französische Ohren klang seine Begründung, in Deutschland unterscheide man zwischen "staatlichem Bewußtsein“ und einem „Gemeinschaftsbewußtsein als Volk, als historisch gewachsene, kulturelle Einheit, die von altersher über die staatlichen Grenzen hinausreichte" und zu welcher eben auch das Elsaß gehöre ${ }^{205}$. Obwohl Reusch die nachbarlichen Grenzen im selben Atemzug für unverletzlich erklärte, beschuldigte ihn ein französischer Zuhörer sofort des Pangermanismus. Andere waren auf Nachfragen von Abetz zwar bereit, sich bei den zuständigen Stellen gegebenenfalls für den Erhalt deutschen Kulturgutes zu verwenden, insistierten aber, daß es sich grundsätzlich um eine rein innerfranzösische Angelegenheit handele ${ }^{206}$. Erneut erschwerten Vokabeln mit betont landesspezifischer Konnotation wie „Volkstum“, „Nation“ oder „sécurité", für die Gegenseite verwirrend oder von vornherein negativ besetzt, eine unvoreingenommene Debatte. Definitorische Hilfestellung sollte künftig ein von François Berge angeregtes zweisprachiges politisches Glossar leisten, einer der seltenen produktiven Vorschläge während der Mainzer Tagung ${ }^{207}$.

Ein Bild, das betroffen machte, zeichnete der Karlsruher Jugendpfarrer Heinz Kappes von der verzweifelten Lage junger Arbeitsloser. Der Besuch eines Arbeitslagers, das existenzgefährdete Jugendliche vor dem völligen Abrutschen bewahren sollte, unterstrich seine Ausführungen ${ }^{208}$. Der in Frankfurt lehrende belgische Sozialist und Soziologe Hendrik de Man beleuchtete Zusammenhänge zwischen ökonomischer Krise und politischem Extremismus, sozialen Ressentiments und übersteigertem Nationalismus ${ }^{209}$. Seiner Auffassung, daß der Nationalismus in wachsendem Maße den Frieden bedrohe, widersprachen sowohl deutsche als auch französische Rechtsradikale, etwa mit dem Hinweis, daß „dem wirklichen Nationalismus [...] jeder Angehörige seines Volkes zu wertvoll [ist], als daß er ihn in einem sinnlosen Krieg opfert". Auf Rüstung wollten sie freilich nicht verzichten - diese Haltung, belehrte einer seine Zuhörer, resultiere „aus einem Ehren-

${ }^{203}$ Maaß, Ungewisses Deutschland?, ebenda, S. 7; vgl. die Ausführungen des Freideutschen Ludwig Oppenheimer „Zum Problem der Reparationen“, S. 19, ausführlich in Notre Temps, Sp. 486 ff., sowie Reusch, Drittes deutsch-französisches Treffen, S. 16.

204 Sohlbergkreis III-IV, S. $18 \mathrm{f}$.

205 Reusch, Die Revision der Friedensverträge, ebenda, S. $16 \mathrm{f}$.

206 Ebenda, S. 18.

207 Reusch, Drittes deutsch-französisches Treffen, S. 16. Ob das Projekt verwirklicht wurde, ist nicht bekannt.

${ }^{208}$ Kappes, Die Lage des jungen deutschen Arbeitslosen, in: Sohlbergkreis, S. 10; vgl. Notre Temps, Sp. $462 \mathrm{ff}$.

209 de Man, Uber den sozialen Wandel in Deutschland; Sohlbergkreis, S. 10f.; Notre Temps, Sp. $469 \mathrm{ff}$. 
standpunkt. Ein Mann ist stolz auf seine Kraft und ein Volk ist stolz auf seine Waffen. “210 So fand denn Hans Hartmanns Vorschlag, stufenweise vorzugehen und zunächst einmal in allen Ländern die Angriffswaffen zu verschrotten, wenig Resonanz. Hartmann meinte, anschließend sollten die Regierungen zusammen mit autorisierten übernationalen Jugendgremien in gewissen Zeitabständen prüfen, ob das aktuelle Sicherheitsgefühl der Völker die Abschaffung weiteren militärischen Geräts zulasse. Ein solches Procedere böte nicht nur der Rüstungsindustrie genügend Frist, ihre Produktion umzustellen, sondern auch Spielraum, die Denkgewohnheiten der Menschen zu ändern und die mentale Abrüstung voranzutreiben211. Den hieran anknüpfenden Vorschlag eines Franzosen, eine europäische Armee als gleichsam „höhere Form der Friedenswache auf unserem Kontinent" zu bilden, begrüßte Abetz wärmstens, vorausgesetzt, das über Einsätze beschließende Kontrollorgan hätte andere völkerrechtliche Grundlagen als den Versailler Vertrag. Anderenfalls würde lediglich ein Zustand verlängert, „den wir alle als unerträglich empfinden" 212 .

Ungebrochen war die Begeisterung, die Kultur des Nachbarlandes näher kennenzulernen. Eine Exkursion nach Frankfurt bot Gelegenheit, den dortigen Feierlichkeiten zum 100. Todestag Goethes beizuwohnen. In den Gewölben der Zitadelle wurde eine Kunstausstellung organisiert, Nachwuchsmusiker brachten eigene Kompositionen und Werke zeitgenössischer Meister zu Gehör. Eine Bücherschau präsentierte mehrere dutzend Proben schöngeistigen und zeitkritischen Schrifttums, deren Lektüre man sich gegenseitig empfahl213. Doch obschon das Lob reichlich ausfiel, taugten auch diese Aktivitäten nur bedingt, Gemeinschaftsbewußtsein zu erzeugen, geschweige die Stagnation in den politischen Debatten aufzuwiegen. Bei näherem Hinsehen sticht wiederum das Bemühen der Gastgeber ins Auge, in Konzeption und Interpretation des Dargebotenen vaterländische Tugend und Größe - oder was man dafür hielt - herauszukehren. Unterschiedliche künstlerische Ansätze wurden sorgsam gegeneinander abgegrenzt und als typisch für den jeweiligen Nationalcharakter gedeutet. Während die Gäste eine breite Palette moderner französischer Malerei zeigten und zu unbefangener Bewertung einluden, war eine durch zahlreiche Leihgaben ermöglichte Schau deutscher Graphik repräsentativ angelegt, bezüglich der Werkauswahl wie des didaktischen Hintergedankens: Gerade dieses Genre mit seiner „zugrunde liegenden Tendenz zum Kollektiven" fessele den deutschen Ausdruckswillen seit jeher ganz besonders, erläuterte der Direktor des Wiesbadener Museums, Frhr. Schenk v. Schweinsberg ${ }^{214}$. Auch die deutsche Literaturauswahl, Ergebnis einer Umfrage bei Jugend- und Studentenverbänden nach den "kennzeichnendsten und maßgeblichsten" Publikationen, beanspruchte, "die Seele unseres Volkes" zu spiegeln; hervorstechende Qualifikation der Autoren sei ihr Wissen um die Not im Lande,

210 Sohlbergkreis, S. 12.

211 Ebenda, S. 13 f.; Notre Temps, Sp. 465 f.; vgl. Hartmann, Die Jugend baut Brücken, S. 368 .

212 Sohlbergkreis, S. $14 \mathrm{f}$.

${ }^{213}$ Das kulturelle Rahmenprogramm ist zusammenfassend dokumentiert ebenda, S. $21 \mathrm{ff}$.

214 Ebenda, S. $24 \mathrm{f}$. 
„ihre Deutschheit, [ihr] Kampf gegen die hohle Phrase, ihre aufrechte und saubere Gesinnung "215. Unter solchen Prämissen lag der Schwerpunkt bei nationalkonservativen Schriftstellern, bei geistigen Wegbereitern des Nationalsozialismus, Kriegserlebnis und Heimat idealisierenden Romanen ${ }^{216}$. Vergleichsweise vielseitig - mit linkem Einschlag - einmal mehr das französische Angebot: Unter dem vorwärts weisenden Motto "Les guides spirituels de la France de demain " wurden bevorzugt Bücher junger Autoren präsentiert, von denen etliche noch am Anfang ihrer literarischen Karriere standen ${ }^{217}$.

Ob politischer Diskurs oder musisch inspirierter Gedankenflug - die einst leuchtende Perspektive von der ausgleichstiftenden Vorreiterrolle einer über Landesgrenzen verschworenen Jugend, die „als zukunftsgerichtete Gegenelite zu den überlebten herrschenden Mächten "218 ein neues Kapitel in den deutsch-französischen Beziehungen aufschlagen wollte, flackerte in Mainz allenfalls sporadisch auf, wenn überhaupt, dann aus französischem Munde vorgetragen ${ }^{219}$. Das hehre Ziel war viel zu weit. Die Bewegung steckte unverkennbar in der Sackgasse, drohte - letztlich verkleinertes Abbild der krisenhaften Gesamtentwicklung - an ideologischem Gezänk und nationalem Prestigedenken zu zerbrechen. Sensiblen Gemütern blieb dies nicht verborgen. „Vielleicht laufen auch Veranstaltungen wie die des Sohlbergkreises sich leer und sind nach einer bestimmten Zeit erschöpft", schrieb Alexander Roßmann in einem kritischen Beitrag für die Kölnische Zeitung. Er machte die schwierigen politischen, wirtschaftlichen und sozialen Verhältnisse verantwortlich, die eigentlich nur noch Versammlungen von Spezialisten sinnvoll erscheinen ließen, und orakeite, künftige Begegnungen könnten „noch mehr Versuch sein“ als die Mainzer Tagung. Angesichts der „rückläufigen Bewegung, die man, vom Sohlberg ausgehend, verfolgen kann“, müßten „neue Wege“ gesucht, „regenerative Kräfte" zugeführt werden, „um aus dem Versuchsstadium wieder zu einer festen Form zu gelangen"220. Die Hoffnungen richteten sich vor allem auf den kulturellen Austausch, unverfänglicher als das politische Fach und stetig im Aufwind begriffen. Damit verbunden waren neuerliche Appelle, das gemeinsame zivilisatorische Erbe, das zu konstruktiver Lösung der drängenden Probleme ermahne, zu bewahren 221 . Im Rahmen dieser großen, verantwortungsvollen Aufgabe hätten die Tagungen des Sohlbergkreises ihren Sinn, befand Wal-

$215 \mathrm{Vgl}$. die einführenden Worte des Neudeutschen Rudolf Fechter, Neues für den Westen. Eine Schau noch nicht übersetzter deutscher Bücher der Nachkriegszeit, ebenda, S. 21 f.; dort auch ein Verzeichnis der ausgestellten Bücher. Notre Temps, Sp. $455 \mathrm{f}$.

216 Eine detaillierte Zuordnung nach Themen und Autoren bei Unteutsch, Sohlbergkreis, S. $70 \mathrm{f}, 262 \mathrm{f}$.

217 Einzelheiten ebenda, S. 71 f. Ein Großteil des Kontingents wurde dem Sohlbergkreis geschenkhalber überlassen und als Grundstock für eine geplante französische Bibliothek dankbar in Empfang genommen; Sohlbergkreis III-IV, S. 32.

218 Tiemann, Nachwuchseliten für die Verständigung?, in: Hudemann/Soutou (Hrsg.), Eliten, Bd. 1, S. 105.

219 Vgl. Louis Martin-Chauffier, Clercs d'après-guerre en France, in: Sohlbergkreis, S. 26f.; Notre Temps, Sp. $476 \mathrm{ff}$.

220 Roßmann, Deutsch-französische Jugendaussprache, in: Kölnische Zeitung, 18. 4. 1932.

221 So der katholische Bonner Theologe Prof. Alois Dempf, Erbe und Gegenwart, in: Sohlbergkreis, S. 31 f.; Notre Temps, Sp. 490 ff. 
ther Reusch, wenngleich sich die Frucht dieser Arbeit erst später zeigen werde. „Man kann höchstens ihre Erfolgsaussichten beurteilen; sie bestimmen sich nach dem geistigen Einfluß, den die Anregungen eines solchen Treffens bei der Jugend des anderen Volkes haben. Es läßt sich nicht verkennen, daß solche Wirkungen vorhanden sind."222 Ein ähnlich zuversichtliches, Bergstraessers Theorie der „kulturellen Begegnung“ verpflichtetes Resümee zog Hans Hartmann: „Diese Art der direkten Kulturvergleiche hat sich als fruchtbar erwiesen und sollte überall, wo es möglich ist, in ähnlicher Weise versucht werden. Das Interesse haftet an den unmittelbaren Eindrücken noch viel lebendiger, als an den ewig wiederholten theoretischen Ausführungen“223.

Aber auch der Kulturaustausch diente, wie gezeigt, zumindest den Deutschen in steigendem Maße zur Abgrenzung und Absicherung, nicht primär als Medium zur Überbrückung nationaler Positionen. Die mehrfach angemahnte „Revision der Mentalitäten" 224 blieb trügerisches Stückwerk. Bedeutsamer als die Vermittlung von Fakten sei, „was wir heute Haltung nennen“, betonte Walther Reusch ${ }^{225}$. Es ist nicht ersichtlich, daß Abetz sich dem Sog dieser Entwicklung, verstärkt durch innen- und außenpolitische Zuspitzungen, entgegengestemmt hätte. Ausweislich der Tagungsberichte ist er in Mainz, anders als in den Jahren zuvor, nicht mehr als charismatische, mit flammenden Appellen Eintracht einfordernde Leitfigur in Erscheinung getreten. Zwar vermochte er über den Tellerrand hinauszublicken, war Frankreich und seinen Menschen zugetan und bemüht, die Faszination des Landes anderen zu erschließen. Der Notwendigkeit einer konstruktiven Neugestaltung der deutsch-französischen Beziehungen gewahr, hatte er sich der selbstgewählten Aufgabe verschrieben, die Öffentlichkeit für diese brennende Gegenwartsfrage zu interessieren, überspannte Ressentiments abzutragen und an gütlichen Lösungen mitzuwirken, um neuen kriegerischen Verwicklungen vorzubeugen. Im Kern aber war er Revisionist, moderat zwar und ohne Hang zur Gewalt, jedoch - weltanschaulich geprägt durch seine Sozialisation in der bürgerlichen Jugendbewegung - den virulenten Theorien von Volk, Raum und Führertum näher als Schranken durchbrechendem Nonkonformismus, ein Schwarmgeist und pragmatisches Einvernehmen mit der Obrigkeit suchender Stratege zugleich, parteiischer als er es sich eingestehen mochte, ein energischer Anwalt traditioneller deutscher Interessen, der, einer mächtigen Zeitströmung folgend, karrierebewußt, aber nicht frei von Zweifeln, in nationalistisches Fahrwasser geriet. Seine gegenläufigen Anlagen begründeten einen nie überwundenen Zwiespalt des Handelns und der erzielten Wirkung, obschon seine subjektive Weltsicht alle Widersprüche beiseite schob. Sie prädestinierten ihn zum Werkzeug der Verständigungsbereitschaft vortäuschenden Frankreichpolitik Hitlers nach 1933.

Im privaten Bereich machte die deutsch-französische Annäherung Fortschritte: Am 1. September 1932 heiratete Otto Abetz in Karlsruhe Suzanne Sidonie de Bruyker, Luchaires Sekretärin. Die beiden hatten sich in Rethel kennengelernt.

222 Reusch, Drittes deutsch-französisches Treffen, S. 19.

223 Hartmann, Die Jugend baut Brücken, S. 369.

224 Vgl. Sohlbergkreis, S. 17, $19 \mathrm{f}$.

225 Reusch, Drittes deutsch-französisches Treffen, S. $19 \mathrm{f}$. 
Amüsiert verfolgten die Bewohner der Villa des Ternes, Domizil der Luchaires und Redaktionsquartier, wie sich die zarten Bande festigten, bis Abetz eines Tages Freund Jean halb förmlich, halb theatralisch um die Hand seiner Mitarbeiterin bat, die er nach Deutschland zu entführen gedachte ${ }^{226}$. Suzanne, geboren am 27. Juli 1899, Weberstochter, stammte aus einer kinderreichen flämischen Familie, die um die Jahrhundertwende nach Lille gezogen und kurz vor Ausbruch des $\mathrm{Er}$ sten Weltkriegs von den französischen Behörden naturalisiert worden war. 1928/ 29 war sie als Angestellte der Tageszeitung $L a$ Voix erstmals einige Monate für Luchaire tätig. Nach einjährigem Sprachkurs in England, wo sie bei einer Familie in Oxford lebte, stieß sie 1930 zur Redaktion von Notre Temps ${ }^{227}$. Luchaires älteste Tochter Corinne beschrieb sie als intelligent, kultiviert, zurückhaltend, doch von einigem Einfluß auf den Vater, der ihren Rat schätzte ${ }^{228}$. Jacques Nels erinnert eine zierliche Person, nicht auffallend hübsch, aber von freundlichem Wesen und der Reputation ihres Gatten förderlich: „Le mariage nous parut un témoignage des bonnes intentions d'Abetz envers la France et les Français. “229 Bei ihrer Vernehmung 1945 sagte Madame Abetz, die durch die Eheschließung die deutsche Staatsbürgerschaft erlangte, sie sei von denselben Idealen beseelt gewesen wie ihr Mann und habe sein Bemühen, die junge Generation beider Länder zusammenzubringen, nach Kräften unterstützt. Im Oktober 1933 gebar sie einen Sohn, Bernhard, den der Schriftsteller Jules Romains als lebendes Symbol des voranschreitenden Aussöhnungsprozesses pries ${ }^{230}$.

226 Corinne Luchaire, Ma drôle de vie, S. 63.

227 Diese Einzelheiten nach: Gouvernement militaire de la zone française d'occupation, Délégation Supérieure pour le Gouvernement militaire du Württemberg, Contrộle de la Sûreté, Niederschrift eines Verhörs von Suzanne Abetz am 31.10.1945 in Tübingen; AN, F 7/15331, Nr. 204/45bis. Weitere biographische Details finden sich im Protokoll einer Vernehmung von Otto Abetz durch SS-Richter am 7. 12. 1937, pag. 8; BDC/Abetz. Siehe auch Das offene Problem, S. 34. In den SS-Akten wird als Geburtsdatum von Suzanne, abweichend von ihren eigenen Angaben, mehrfach der 28. Juli 1903 genannt.

228 Wie Anm. 226.

229 Nels, Fragments, S. 115.

230 Romains, Sept mystères, S. 237. Abetz' Tochter Sonia wurde im März 1936 geboren. 